\title{
INEQUALITY OF FEAR AND SELF-QUARANTINE: \\ IS THERE A TRADE-OFF BETWEEN GDP AND PUBLIC HEALTH?
}

\author{
Sangmin Aum \\ Sang Yoon (Tim) Lee \\ Yongseok Shin \\ Working Paper 27100 \\ http://www.nber.org/papers/w27100 \\ NATIONAL BUREAU OF ECONOMIC RESEARCH \\ 1050 Massachusetts Avenue \\ Cambridge, MA 02138 \\ May 2020
}

The views expressed herein are those of the authors and do not necessarily reflect the views of the National Bureau of Economic Research.

NBER working papers are circulated for discussion and comment purposes. They have not been peer-reviewed or been subject to the review by the NBER Board of Directors that accompanies official NBER publications.

(C) 2020 by Sangmin Aum, Sang Yoon (Tim) Lee, and Yongseok Shin. All rights reserved. Short sections of text, not to exceed two paragraphs, may be quoted without explicit permission provided that full credit, including $\odot$ notice, is given to the source. 
Inequality of Fear and Self-Quarantine: Is There a Trade-off between GDP and Public Health? Sangmin Aum, Sang Yoon (Tim) Lee, and Yongseok Shin

NBER Working Paper No. 27100

May 2020

JEL No. I14,I18,J24

\begin{abstract}
$\underline{\text { ABSTRACT }}$
We construct a quantitative model of an economy hit by an epidemic. People differ by age and skill, and choose occupations and whether to commute to work or work from home, to maximize their income and minimize their fear of infection. Occupations differ by wage, infection risk, and the productivity loss when working from home. By setting the model parameters to replicate the progression of COVID-19 in South Korea and the United Kingdom, we obtain three key results. First, government-imposed lock-downs may not present a clear trade-off between GDP and public health, as commonly believed, even though its immediate effect is to reduce GDP and infections by forcing people to work from home. A premature lifting of the lock-down raises GDP temporarily, but infections rise over the next months to a level at which many people choose to work from home, where they are less productive, driven by the fear of infection. A longer lockdown eventually mitigates the GDP loss as well as flattens the infection curve. Second, if the UK had adopted South Korean policies, its GDP loss and infections would have been substantially smaller both in the short and the long run. This is not because Korea implemented policies sooner, but because aggressive testing and tracking more effectively reduce infections and disrupt the economy less than a blanket lock-down. Finally, low-skill workers and self-employed lose the most from the epidemic and also from the government policies. However, the policy of issuing "visas" to those who have antibodies will disproportionately benefit the low-skilled, by relieving them of the fear of infection and also by allowing them to get back to work.

Sangmin Aum

Myongji University

34 Geobukgol-ro, Seodaemun-gu

Seoul 03674

South Korea

aumsang@gmail.com

Sang Yoon (Tim) Lee

Queen Mary University of London

Mile End Road

E1 4NS London

United Kingdom

and CEPR

sylee.tim@qmul.ac.uk

Yongseok Shin

Department of Economics

Washington University in St. Louis

One Brookings Drive

St. Louis, MO 63130

and NBER

yshin@wustl.edu
\end{abstract}




\section{Introduction}

As the COVID-19 pandemic went under way, with no known vaccine or cure, most governments turned to quarantine policies to "flatten the curve." Some of the policies are selective and targeted, based on testing and tracing, while others were more blunt, indiscriminately imposing social distancing and lock-downs. The urgency of the situation and the lack of real-time data have not allowed a thorough analysis of the economic and epidemiological impact of such policies. Which policy is more effective in arresting the epidemic? How big are the economic costs of the quarantine policies that disrupt most economic activities? How are the impacts of the epidemic and the governments' countermeasures distributed across people of different socioeconomic standings? These questions remain largely unanswered. In the midst of the intense debates on whether to open up to save the economy or to stay locked down till the epidemic further subsides, addressing these questions is of paramount importance.

To answer the questions, we develop a quantitative economic-epidemiological model, in which the progression of the epidemic affects people's economic decisions and vice versa. The model has several novel features that make it unique in the nascent but fast growing literature of epidemic economics. First, to evaluate how the impact of the epidemic and the policies are distributed, the model incorporates rich heterogeneity: People differ by skill and age, and there are multiple sectors and occupations. Second, people choose their occupations and whether to commute to work or work from home, to maximize income and minimize the fear of infection. Occupations are different in terms of earnings, infection risks, and the productivity loss when working from home. Working from home entails lower earnings but curtails the risk of infection. Third, true health states are not observable, and people have to be tested to find out their current infection status (or past status, if antibody tests are available) subject to false negatives. Finally, governments have access to three policy tools: testing, tracing/tracking (targeted quarantine), and broad lock-downs. The intensive margins of these tools are adjustable, and so is their timing.

Our model provides a framework for quantitative analysis and can be used to evaluate and predict the aggregate and distributive effects of real-world policies in various economic settings. The quantitative nature of our analysis sets it apart from most other works in the literature, which tend to be either empirical or theoretical. In this paper, we choose the model parameters to replicate the progression of COVID-19 in South Korea and the United Kingdom (henceforth SK and UK, respectively). These two make an interesting and informative contrast. SK responded early with aggressive testing and tracking, and largely contained the epidemic. The UK on the other hand belatedly imposed a blanket lock-down, and its containment efforts have not been as successful.

Based on our quantitative analysis of the two countries, we obtain three key results.

First, contrary to the common view, there may not be a clear trade-off between GDP and public health after all. It is true that, since a lock-down prevents people from working normally, it can slow down the rise in infection at the expense of lower economic output. It is also true that a premature lifting of the lock-down increases GDP initially at the expense of rising infections. However, if the lock-down is lifted too soon, infections can rise to a level at which most people voluntarily work from home out of fear of infection, and this would happen in a matter of months. The government may try to impose another round of lock-downs, but all the countermeasures lose their 
potency once infections reach a certain threshold. For the UK, an extended lock-down will lead to 150,000 fewer infections and 5-percent higher GDP by November than the current policy. In other words, a stricter and longer lock-down can deliver both higher GDP and better public health outcomes.

Second, if the UK had adopted the SK policies, its GDP loss would have been smaller by two-thirds both in the short and the long run, and the cumulative infections through November would have been smaller by 70 percent. This is not merely because SK implemented policies sooner: The model shows that an earlier implementation of the lock-down in the UK has minor effects on GDP and infection. Rather, it is because aggressive testing and tracking can more effectively isolate the infected and hence reduce their chance of infecting other people, without forcing everyone, including the large majority that is not infected, to work from home where they are less productive.

Third, the epidemic or the policies implemented to counter it do not affect people equally. Low-skill jobs tend to be more contact-intensive (e.g., restaurants and retail), which means that (i) low-skill individuals face higher infection risks and hence suffer more from the fear of infection, and (ii) it is hard to do their work from home and hence their earnings loss when working from home is larger. For these reasons, lowskill workers and self-employed are disproportionately affected by the epidemic and the government's countermeasures that make them work from home (be it through testing, tracking and/or lock-down), and some low-skill workers in particular switch jobs in response. One exception is the potential policy of issuing "virus visas" to those who have antibodies: This policy will disproportionately benefit the low-skill workers and self-employed, by relieving them of the fear of infection and also by allowing them to get back to work. A visa policy can raise UK's GDP by 10 percent compared to its baseline lock-down policy in our model, entirely driven by a 20-percent higher output in low-wage sectors. This result suggests that antibody tests should prioritize the lowskilled, not only to help those most in need, but also to have a maximal positive effect on aggregate GDP.

Related literature Our paper belongs to the new strand of literature that incorporates the SIR epidemiology model by Kermack et al. (1927) or its variants into economic environments. Our innovation on the epidemiology side is to consider asymptotic carriers, which is crucial in the evaluation of testing policies, and heterogeneous infection rates by worker type, which can alter the spread of the virus depending on which people are quarantined. For the production structure, we use a simplified version of our existing work on sector/occupational heterogeneity in Lee and Shin (2017), and refer to Hensvik et al. (2020) to guide our choice of work-from-home productivity differences across sector-occupations, as well as which jobs are more "essential" in the event of a lock-down.

Insofar as we focus on the quantitative impact of virus containment policies to gauge the interaction between economic activities and the spread of the virus, our paper is related to the more theoretical papers such as Alvarez et al. (2020), Eichenbaum et al. (2020), and Piguillem and Shi (2020) that analyze optimal quarantine policies considering similar trade-offs. In particular, Piguillem and Shi (2020) is closest to our work in that theirs is the only other model that is calibrated to actual data moments (Italy), and highlights the effectiveness of testing policy under the possibility of asymptotic carriers. We expand on such papers by considering a more elaborate heterogeneous-agent 


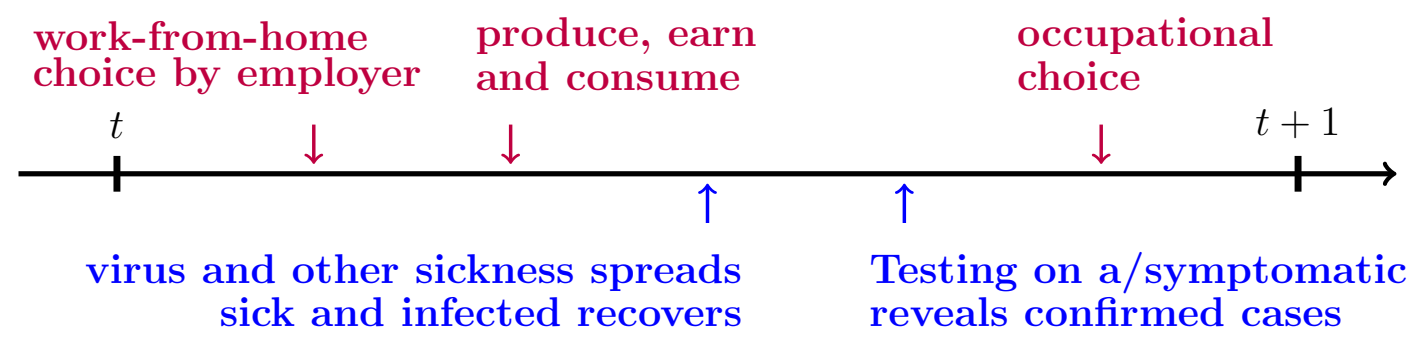

Fig. 1: Model Timeline

equilibrium model of production in which people voluntarily choose to self-quarantine themselves out of fear and are unaware of their own infection status without testing. We also consider different dimensions of government-enforced quarantines (ordering people to stay home is different from enforcing that order, e.g. lock-down orders vs. SK-style digital tracking).

The (potential) importance of voluntary self-quarantine in response to the epidemic shock is also emphasized in Farboodi et al. (2020) and Chudik et al. (2020). The latter argues that self-quarantine is unlikely to lower infection rates unless the epidemic approaches very high levels, so that mandated social distancing could be required to flatten the epidemic curve, which we find to be true in our calibration. But we focus on the quantitative impact on GDP and inequality, while Chudik et al. (2020) focus on the estimation of the epidemiology parameters. Krueger et al. (2020) consider heterogeneity in individuals' consumption choices, and show that an endogenous shift of consumption toward low contact goods from high contact goods can mitigate the negative impact on the economic activity. In contrast, we focus on the heterogeneity in individuals' labor supply choices, and delve deeper into distributional issues in addition to the aggregate impact of COVID-19.

We explicitly model the fact that high levels of voluntary self-quarantine leads to GDP losses, as well as how self-quarantine interacts with various policy options, concluding that the combination of test/trace/tracking is the most effective tool from both an economic and epidemiology perspective. To our knowledge, this paper is the first quantitative analysis that explicitly fits both country level data on GDP and employment in conjunction with COVID infection/death counts, as well as inequality in both economic and epidemiological outcomes.

\section{Model}

Time is discrete, and one model period is one day. At $t=0$, there is an influx of infected agents into the economy, but nobody is aware of it until the government starts testing at some later date $\tau>0$. We allow for asymptomatic carriers and also for similar symptoms not caused by the coronavirus: People could show no symptom when infected with the coronavirus, and could exhibit similar symptoms without the coronavirus (e.g., sick with the flu). People start the day with a health status and in the job they chose last night (either the same job as yesterday or a new job), and in the morning, decide whether to commute or work from home. Then they work 
and consume, and prices are determined to clear markets. Over the course of the day, the virus spreads, and some of the infected people recover. Their health status (symptomatic/asymptomatic) also gets updated. In the evening, if $t \geq \tau$, people may get tested. Given the test results and their updated health status, they decide whether to stay in their job or switch to a new job. The whole cycle repeats itself the next day.

Below, we describe the model details without a time-subscript: all choices are made between morning and night. The model's daily timeline is shown in Figure 1.

\subsection{Individual States}

Immutable states People are either young or old, and given the focus on the short-term dynamics, we ignore aging. People do die with or without COVID-19 and exit from the model. The old are all retired and do not work. We will also assume that all of the old are in self-quarantine in the presence of COVID-19. These assumptions imply that the model treats the old as a single block, although their epidemiological states to be defined below will differ from one another and change over time.

On the other hand, the young are either high-skilled or low-skilled, indexed by $x \in$ $\{l, h\}$, which is a permanent characteristic. In every period, they choose occupations and, unlike the old, may or may not be in quarantine. Like the old, their epidemiological states are heterogeneous and change over time.

In summary, one's age (young or old) and skill (only for the young) are held permanently constant.

True epidemiological states The true epidemiological side of the model extends the SIR model, and we have four states: susceptible $(\mathrm{S})$, infected (I), recovered (R) and dead (D). Needless to say, death is an absorbing state. We assume that those recovered will not be infected again, although this is not a foregone conclusion in the medical literature.

One important distinction we make is that these true epidemiological states, with the exception of death, are not observable to the people or the government in the model. As a result, they will make decisions based on observed epidemiological states defined below.

Observed epidemiological states People are either healthy (asymptomatic, $a$ ) or sick (symptomatic, s), both with and without the SARS-CoV-2 ("the virus" hereafter). By now it is well known that some people with the virus exhibit no symptom. In addition, in the model it is possible that someone without the virus can be sick with symptoms (for example, because of the flu) similar to those of COVID-19. In terms of testing for the virus, people fall into three categories: untested or tested negative (superscript 0), tested positive (superscript $c$ ), and confirmed remission (superscript $r$ ). False negative is a possibility, but false positive is not. As a result, we have seven observed epidemiological states: two symptom categories by three test categories, plus death: $\left\{a^{0}, s^{0}, a^{c}, s^{c}, a^{r}, s^{r}, d=D\right\}$. The true and observed epidemiological states coincide perfectly only at death. The two diverge because not everyone is tested and also false negative is possible. 


\subsection{The Economic Model}

Preferences and Technology For utility out of consumption, we assume that

$$
u(c)=\log (1+c),
$$

which is somewhat unconventional but it is equivalent to Stone-Geary log-preferences with one unit of "free consumption." This is to allow for zero earnings. We will also introduce additively-separable disutility terms coming from the epidemiological side.

There are three sectors of production. Two of them produce intermediate inputs and are labeled "high-skill" and "low-skill" in reference to the skill levels of the people who work in them. The other is the final good sector, combining the output of the high- and the low-skill sectors with a constant-return-to-scale production function:

$$
Y=Y_{l}^{\theta} Y_{h}^{1-\theta}
$$

where $0<\theta<1$ is a share parameter. The production is done by a perfectlycompetitive, representative firm, and the final good price $p$ is normalized to one.

For the high-skill and the low-skill sectors, indexed by $x=h, l$, there are two modes of production. First, a healthy self-employed person who commutes to work produces $z_{x, 1}$ units of the skill- $x$ good without hiring any additional labor, where the subscript 1 denotes self-employment. Second, a healthy manager who commutes to work, and whose skill is $x$ can hire workers of the same skill and operate a span-ofcontrol production function:

$$
y_{x, 2}=z_{x, 2}^{\alpha_{x}} l_{x, 3}^{1-\alpha_{x}}
$$

where $z_{x, 2}$ is the efficiency unit as a manager (subscript 2) of skill $x$ and $l_{x, 3}$ is the efficiency units of the workers (subscript 3) of the same skill $x$ hired. The parameter $1-\alpha_{x}$ is the span of control. The skill- $x$ output produced by the two modes are perfectly substitutable. The price of the high- and the low-skill goods are denoted by $p_{h}$ and $p_{l}$ respectively, and all producers are price takers.

\subsubsection{Individual Choices}

In the model, the old are retired and always in self-quarantine, and hence have no decision to make. The young will choose their occupation and quarantine status based on their skill and observed epidemiological states.

Work-from-home decision Our timing convention is such that the young choose an occupation at the end of each period. There are three occupations for each of the two skill levels: self-employment (non-employer), manager, and worker, which we index by $j=1,2,3$. Having entered the current period with a given occupation, the self-employed decide whether to work from home (self-quarantine) or work normally (not in quarantine), and the managers decide whether they and/or their workers will work from home or not. Workers do not have such a decision - they are told by their managers to either work normally or work from home.

Working from home makes people less productive, and their efficiency units are multiplied by a factor $\psi_{x, j}$ that is less than one, which varies by the two-by-three 
skill-occupation groups. We assume that low-skill occupations' $\psi_{x, j}$ is smaller than high-skill occupations', consistent with observed patterns of telecommuting.

Sick people are less productive whether they work normally or from home, so the efficiency units are multiplied by a factor $\phi$ that is less than one if and only if sick (symptomatic, $e \in\left\{s^{0}, s^{c}, s^{r}\right\}$ ), regardless of whether or not they have the virus. In addition, working normally (not in quarantine) while sick causes disutility $\kappa$. This productivity loss and the disutility from working while sick are the same for all skilloccupation groups.

The wage per efficiency unit of high-skill labor is $w_{h}$ and that of low-skill labor is $w_{l}$. For tractability, we assume that when making the work-from-home decision, the self-employed and managers use adaptive expectations and base their decisions on the equilibrium prices from the previous period.

The self-employed (subscript 1) with skill $x$ and observable epidemiological state $e$ choose to work normally $(n)$ or work from home $(q)$ :

$$
V_{x, 1}(e ; \mathbf{p})=\max _{\iota \in\{n, q\}}\left\{V_{x, 1}^{n}(e ; \mathbf{p})+\epsilon_{n}, V_{x, 1}^{q}(e ; \mathbf{p})+\epsilon_{q}\right\},
$$

where $\epsilon_{\iota}$ for $\iota=n, q$ is i.i.d. extreme value preference shocks. The work location choice is made after the realization of the preference shocks. The aggregate state $\mathbf{p}$ is the vector of market-clearing prices and wages from the previous period. The two values of working normally and from home are

$$
\begin{aligned}
& V_{x, 1}^{n}(e ; \mathbf{p})=u\left[\phi(e) \cdot p_{x} z_{x, 1}\right]-\kappa(e)-\chi_{x, 1}(\mathbf{I}, e) \\
& V_{x, 1}^{q}(e ; \mathbf{p})=u\left[\psi_{x, 1} \phi(e) \cdot p_{x} z_{x, 1}\right]-\chi_{q}(\mathbf{I}, e) .
\end{aligned}
$$

The self-employed with skill $x$ produce $z_{x, 1}$ units of output without using any input, and the output price is $p_{x}$. The parameter $\psi_{x, 1}<1$ discounts their productivity when working from home, which differs by skill $x$. The reduced productivity for being sick $\phi(e)$ is less than one for $e \in\left\{s^{0}, s^{c}, s^{r}\right\}$ and equal to one otherwise. The pecuniary utility from hand-to-mouth consumption is the first term. Individuals also dislike working normally while sick and would rather work from home, as measured by $\kappa(e){ }^{1}$ The last term $\chi(\mathbf{I}, e)$ is the disutility from the fear of infection, which differs depending on whether or not an individual chooses to stay at home (effectively quarantining oneself). ${ }^{2}$ Fear depends on the entire distribution of the masses of the infected across all groups (the vector notation $\mathbf{I}$, whose $i$-th element is the mass of those infected in group $i$ ). However, if $e \in\left\{a^{r}, s^{r}\right\}$, the individual knows that he is immune and no longer has this fear. For this reason, testing is an important policy not only because it enables us to quarantine those tested positive $\left(e \in\left\{a^{c}, s^{c}\right\}\right)$, but also because it directly reduces people's fear from infection. ${ }^{3}$

\footnotetext{
${ }^{1}$ This is distinct from a general disutility from being sick, which we ignore as it does not alter choices.

${ }^{2}$ Our reduced form specification can capture a direct disutility from high infections, but also the expected loss in future earnings from becoming infected tomorrow.

${ }^{3}$ People do not know whether they themselves are infected/recovered without testing, and the government does not know who is infected either. However, they still know the total number of infected by skill, occupation, and observed health status, as long as they know the deterministic epidemiological laws of motion in Section 2.3 and the history of confirmed cases. This is why $\mathbf{I}$ is an admissible argument of individual preferences.
} 
Similarly, the values of managers of skill $x$ (subscript $x, 2)$ working normally $(n)$ or from home $(q)$ are:

$$
\begin{aligned}
& V_{x, 2}^{n}(e ; \mathbf{p})=u\left[\phi(e) \cdot \pi_{x} z_{x, 2}\right]-\kappa(e)-\chi_{x, 2}(\mathbf{I}, e) \\
& V_{x, 2}^{q}(e ; \mathbf{p})=u\left[\psi_{x, 2} \phi(e) \cdot \pi_{x} z_{x, 2}\right]-\chi_{q}(\mathbf{I}, e) .
\end{aligned}
$$

The main difference from the self-employed is the return to their skill $\pi_{x}$ :

$$
\pi_{x}=\alpha_{x} p_{x} \cdot\left[\frac{\left(1-\alpha_{x}\right) p_{x}}{w_{x}}\right]^{\frac{1-\alpha_{x}}{\alpha_{x}}},
$$

which is the maximized profit per efficiency unit of managerial skill. The managers' productivity discount when working from home, $\psi_{x, 2}$, and their fear from infection, $\chi_{x, 2}(\mathbf{I}, e)$, differ by skill $x$ and also from those of the self-employed or the worker (hence subscript 2).

In addition, managers decide whether their workers will work normally or work from home. For this decision, managers act like a "paternalistic planner" and maximize a modified version of the workers' objective function. Specifically, a manager's problem regarding a worker with skill $x$ and observed health status $e_{x, 3}$ is:

$$
\max _{\iota \in\{n, q\}}\left\{u\left[\phi(e) \cdot w_{x} z_{x, 3}\right]+\epsilon_{n}, u\left[\psi_{x, 3} \phi(e) \cdot w_{x} z_{x, 3}\right]+\epsilon_{q}\right\},
$$

where the first term for each choice captures the worker's utility from consuming his labor income, which is the product of the wage $w_{x}$ and his labor efficiency units $z_{x, 3}$, discounted by $\phi$ for being sick and/or $\psi_{x, 3}$ for working from home. For each worker, the manager draws i.i.d. extreme value preference shocks $\epsilon_{\iota}$ and make the worker's work location decision.

We compare this objective function of the "paternalistic" manager with the actual values of a worker with skill $x$ and observed epidemiological state $e$ for the period:

$$
\begin{aligned}
V_{x, 3}^{n}(e ; \mathbf{p}) & =u\left[\phi(e) \cdot w_{x} z_{x, 3}\right]-\kappa(e)-\chi_{x, 3}(\mathbf{I}, e) \\
V_{x, 3}^{q}(e ; \mathbf{p}) & =u\left[\psi_{x, 3} \phi(e) \cdot w_{x} z_{x, 3}\right]-\chi_{q}(\mathbf{I}, e) .
\end{aligned}
$$

We see that the paternalistic managers completely ignore the disutility from working normally while sick $\kappa$ as well as their fear when making the work-from-home decision.

Due to the extreme value assumptions on the preference shocks for work location, the fraction of the self-employed, managers and workers working from home, $\operatorname{Pr}_{x, j}^{q}(e, \mathbf{p})$ for $j=1,2,3$, can be easily calculated from the values in equations (4), (5) and (6) as conditional choice probabilities (CCP). Because the workers do not make the work location decision themselves, the values in (6) are used, not those in (7). To be specific, for $j=1,2$,

$$
\operatorname{Pr}_{x, j}^{q}(e, \mathbf{p})=\frac{1}{1+\exp \left[V_{x, j}^{n}(e ; \mathbf{p})-V_{x, j}^{q}(e ; \mathbf{p})\right]} .
$$

In the event of a lock-down, the government force people to work from home. Let $\rho_{x, j}(e)$ denote the fraction of people of skill-occupation $x-j$ with epidemiological state $e$ prevented from commuting to work. Then the actual fraction of people who stay home is

$$
\overline{\operatorname{Pr}}_{x, j}^{q}(e, \mathbf{p})=\max \left\{\rho_{x, j}(e), \operatorname{Pr}_{x, j}^{q}(e, \mathbf{p})\right\} .
$$


Occupational choice At the end of each period, after production takes place and everyone's true and observable epidemiological states are updated, the young choose occupations for the next period subject to an important friction: Only a fraction $\nu<1$ of those who want to switch occupations can do so. This assumption prevents unrealistically high volumes of occupation changes at a high frequency. (A period in the model is a day.)

The occupation choice is myopic: People will choose the occupation that maximizes the current period profit/wage minus the disutility of working while sick and the disutility from the fear of getting infected. This is a static choice but the last term captures a notion of continuation value. When making the decision, they have updated information about their status $\bar{e}$, which they know from testing, and also about realized market clearing prices of today, $\overline{\mathbf{p}} .{ }^{4}$ The values also include i.i.d. extreme value preference shocks $\epsilon_{j}$ for each occupation, and people are aware that tomorrow's work-from-home decision will be subject to the same i.i.d. extreme value preference shock $\epsilon_{\iota}$. To be specific, the occupation choice is

$$
\max _{j=1,2,3}\left\{\overline{\operatorname{Pr}}_{x, j}^{q}(\bar{e}, \mathbf{p}) \cdot V_{x, j}^{q}(\bar{e}, \overline{\mathbf{p}})+\left[1-\overline{\operatorname{Pr}}_{x, j}^{q}(\bar{e}, \mathbf{p})\right] \cdot V_{x, j}^{n}(\bar{e}, \overline{\mathbf{p}})+\epsilon_{j}\right\} .
$$

The values of working normally or from home $(\iota=n, q)$ for a skill-occupation combination $x-j, V_{x, j}^{\iota}$ are defined in equations (4), (5) and (7). The probability of working from home for each occupation is in equations (8) and (9). Note that the realized price vector $\overline{\mathbf{p}}$ that clears the market, and used for occupation choice, is different from the price $\mathbf{p}$ that individuals use to make their work-from-home decisions.

We reiterate that only a fraction $\nu<1$ of those who want to switch occupations are given the opportunity to do so.

\subsubsection{Equilibrium}

Once the work location choices are made as in equations (4)-(6), the wages and the output prices are determined to clear labor and goods markets. The wage per efficiency unit of skill $x$ is

$$
\bar{w}_{x}=\left(1-\alpha_{x}\right) \bar{p}_{x} \cdot\left(\frac{\Lambda_{x, 2}}{\Lambda_{x, 3}}\right)^{\alpha_{x}}
$$

where $\Lambda_{x, j}$ is the total efficiency units of skill $x$ and occupation $j$ supplied, taking into account the occupation-specific productivity $z_{x, j}$, the fraction of sick individuals and sickness discount $\phi$, and the fraction of those working from home and the home discounts $\psi_{x, j}$.

Since the two intermediate goods indexed by skill $x$ are combined by a CES function to produce the final good, the intermediate good market clearing condition is

$$
\frac{\bar{p}_{h}}{\bar{p}_{l}}=\frac{1-\theta}{\theta} \cdot \frac{y_{l}}{y_{h}}
$$

where $y_{x}$ is the total output of the self-employed and managers of skill $x$, or occupations $(x, 1)$ and $(x, 2)$, taking into account the skill-occupation-specific productivity $z_{x, j}$, the

\footnotetext{
${ }^{4}$ This is a form of "adapted expectations" since the occupation choice is for the next period and hence the resulting market clearing wages and profits will be different from the current values on which the decision is based on.
} 
fraction of sick individuals and sickness discount $\phi$, and the fraction of those working from home and the home discounts $\psi_{x, j}$. The final good is the numeraire and its price, $p$, satisfies

$$
1=\bar{p}=\left(\frac{\bar{p}_{l}}{\theta}\right)^{\theta}\left(\frac{\bar{p}_{h}}{1-\theta}\right)^{1-\theta} .
$$

\subsection{The Epidemiological Model}

The epidemiological side of our model is a heterogeneous-agent version of the SIR model. To be specific, there are eight distinct groups to keep track of: six skilloccupation groups working normally, all the young people working from home (or in quarantine), and the old. For the economic side of the model, we need to keep track of who works normally or at home for each skill-occupation group. However, the epidemiological law of motion applies equally to all the young working from home, regardless of their skill or occupation. As a result we have seven groups for the young rather than twelve (six skill-occupations by two work locations). The old are also in quarantine, but subject to a different epidemiological law of motion.

\subsubsection{True Epidemiological States}

For each of the eight group indexed by $i$, there are four true epidemiological states and their respective mass is denoted by $S_{i}$ (susceptible), $I_{i}$ (infected), $R_{i}$ (recovered), and $D_{i}$ (dead). Let $\mathbf{I} \equiv\left(I_{i}\right)$ be the vector of the masses of the infected across all eight groups. We use bars on the masses to denote the masses at the end of the period. The true epidemiological states for each group $i$ evolve as follows.

$$
\begin{aligned}
\frac{\bar{S}_{i}}{1-\delta_{i}} & =\left[1-v_{i}(\mathbf{I})\right] S_{i} \\
\frac{\bar{I}_{i}}{1-\delta_{i}} & =v_{i}(\mathbf{I}) S_{i}+\left(1-\gamma_{i}\right)\left(1-m_{i}\right) I_{i} \\
\frac{\bar{R}_{i}}{1-\delta_{i}} & =\gamma_{i}\left(1-m_{i}\right) I_{i}+R_{i} \\
\bar{D}_{i} & =D_{i}+\delta_{i}\left(S_{i}+I_{i}+R_{i}\right)+\left(1-\delta_{i}\right) m_{i} I_{i}
\end{aligned}
$$

The baseline death rate is $\delta_{i}$ and the group-specific infection rate as a function of the masses of the infected across the eight groups is $v_{i}(\mathbf{I})$. The recovery rate is $\gamma_{i}$ and the added mortality from the virus is $m_{i}$. In essence, we have eight separate SIR models for the eight groups, linked by the dependence of the infection rates on all groups' infected masses. Note that we assume complete immunity once a patient recovers.

Each period, a fraction of the susceptible dies or becomes infected, and the infection rates depend on the distribution of infected masses across the eight groups. The dependence itself varies across the eight groups (hence $v_{i}(\mathbf{I})$ ). These assumptions allow us to capture the facts that people can get infected more easily by their coworkers (including managers) than by the general public and that sectors may differ in how often their workers may infect their customers. They can also capture the obvious fact that people in quarantine are both less likely to get infected and infect others (those in quarantine are one of the eight groups). Moreover, the function can also capture the effectiveness of tracking or lock-down policies: That is, the government has some 
control over how much it can socially isolate people in quarantine, as we explain in the next section when we specify functional forms for $v_{i}(\mathbf{I})$.

While some of the infected die (baseline death rate $\delta_{i}$ plus the additional mortality from the virus $m_{i}$ ), a fraction $\gamma_{i}$ recovers.

\subsubsection{Observed Epidemiological States}

The true epidemiological states are not observed (with the exception of death), and hence people do not know whether they are susceptible, infected or recovered without testing. Even then, we allow for false negatives. Infected people may not show any symptoms, and the susceptible and even the recovered may show symptoms.

We now explain how we keep track of the observed epidemiological states. We define the mass of the infected that are unconfirmed after infection and recovery take place but before testing is done at the end of the period:

$$
\hat{I}_{i}=\bar{I}_{i}-\left(1-\delta_{i}\right)\left(1-m_{i}\right)\left(1-\gamma_{i}\right) c_{i},
$$

where $c_{i}$ is the mass of the confirmed infected at the beginning of the period. Similarly, we define the mass of the recovered that are unconfirmed after infection and recovery take place but before tests are done at the end of the period:

$$
\hat{R}_{i}=\bar{R}_{i}-\left(1-\delta_{i}\right)\left[\gamma_{i}\left(1-m_{i}\right) c_{i}+r_{i}\right]
$$

where $r_{i}$ is the mass of the confirmed recovered at the beginning of the period. A person is confirmed recovered either if he tests negative after having tested positive or if his recovery is confirmed by an antibody test.

Then at the end of a period, after tests are administered, the mass of the unconfirmed without symptoms $\bar{a}_{i}^{0}$ and the mass of the unconfirmed with symptoms $\bar{s}_{i}^{0}$ for each group indexed by $i$ are

$$
\begin{aligned}
\bar{a}_{i}^{0} & =\left(1-f_{i}\right) \bar{S}_{i}+\left(1-\omega \tau^{a}\right)\left(1-\eta_{i}\right) \hat{I}_{i}+\left(1-\mathbb{I}_{A B} \omega \tau^{a}\right)\left(1-f_{i}\right) \hat{R}_{i}, \\
\bar{s}_{i}^{0} & =f_{i} \bar{S}_{i}+\left(1-\omega \tau^{s}\right) \eta_{i} \hat{I}_{i}+\left(1-\mathbb{I}_{A B} \omega \tau^{s}\right) f_{i} \hat{R}_{i},
\end{aligned}
$$

where $f_{i}$ is the probability of getting sick (symptomatic) when susceptible or recovered and $\eta_{i}$ is the probability of getting sick when infected. Fractions $\tau^{a}$ and $\tau^{s}$ of the asymptomatic unconfirmed and the symptomatic unconfirmed are tested, respectively, and $\omega$ is the probability that the test correctly detects the virus. The indicator function $\mathbb{I}_{A B}$ is one if anti-body tests are available and zero if not. The mass of the asymptomatic unconfirmed $\bar{a}_{i}^{0}$ consists of (i) the susceptible who are not sick, (ii) the asymptomatic unconfirmed infected who get either untested or get a false negative result, and (iii) the asymptomatic unconfirmed recovered who get either untested or get a false negative result for antibody, if antibody tests are available. Similarly, the mass of the symptomatic unconfirmed $\bar{s}_{i}^{0}$ is the sum of (i) the sick susceptible, (ii) the symptomatic unconfirmed infected who are untested or given false positive, and (iii) the symptomatic unconfirmed recovered untested or tested false negative for antibodies.

The masses of the confirmed infected $\bar{c}_{i}$ and the confirmed recovered $\bar{r}_{i}$ after testing at the end of the period are

$$
\bar{c}_{i}=\left(1-\delta_{i}\right)\left(1-m_{i}\right)\left(1-\gamma_{i}\right) c_{i}+\omega\left[\tau^{a}\left(1-\eta_{i}\right)+\tau^{s} \eta_{i}\right] \hat{I}_{i},
$$




$$
\bar{r}_{i}=\left(1-\delta_{i}\right)\left[r_{i}+\gamma_{i}\left(1-m_{i}\right) c_{i}\right]+\mathbb{I}_{A B} \cdot \omega\left[\tau^{a}\left(1-\eta_{i}\right)+\tau^{s} \eta_{i}\right] \hat{R}_{i} .
$$

The mass of the confirmed infected is the previous period's mass net of death and recovery, plus the newly confirmed of the unconfirmed infected. The mass of the confirmed recovered is the previous period's mass net of death, plus those of the confirmed infected who recover this period and, when antibody tests are available, the newly confirmed of the unconfirmed recovered. Obviously, $c_{j}$ and $r_{j}$ are zero from $t=0$ to $t=\tau$, assuming that the virus hits at time 0 and testing begins at time $\tau$.

\subsubsection{Infection Rates}

Let $I$ (with no subscript) denote the total mass of infected in the population, i.e., $I \equiv \sum_{i} I_{i}$ for all $I_{i} \in \mathbf{I}$. We denote by $Q$ the effectiveness of quarantine policies and assume that the mass of the infected who actually spread the disease is

$$
I^{*}=I-Q I_{q}, \quad 0 \leq Q \leq 1,
$$

where $I_{q}$ is the mass of the infected in the quarantine group, $i=q$. In this setup, $Q$ is a policy variable that controls the intensive margin of quarantine policies. ${ }^{5}$ For example, the government can regularly check if people in quarantine are actually staying home by means of digital tracking, such as in SK, or by police-enforced lock-downs, as in most other countries. This is different from the extensive margin of quarantines, which bars people from commuting to work but not checking whether they actually stay home. For example if $Q=1$, all the young people working from home $\left(I_{q}\right)$ are staying home and not infecting anyone. On the other hand, if $Q=0$, all the people working from home actually go around socializing and infecting others.

We now specify the infection rates $v_{i}(\mathbf{I})$ for the eight groups indexed by $i$. First, for the old, those in quarantine, and the self-employed $(i \in\{o, q,(l, 1),(h, 1)\})$, we assume:

$$
v_{i}(\mathbf{I})=\bar{v}_{i} \cdot \frac{I^{*}}{N}
$$

where $N$ is the population size. So their infection rates depend only on the total mass of the infected, net of those effectively quarantined.

For managers and workers working normally, $i \in\{(l, 2),(l, 3),(h, 2),(h, 3)\}$ :

$$
v_{i}(\mathbf{I})=\bar{v}_{i} \cdot\left[\beta_{i}^{i} \cdot \frac{I_{i}}{N_{i}}+\beta_{i}^{k} \cdot \frac{I_{k}}{N_{k}}+\left(1-\beta_{i}^{i}-\beta_{i}^{k}\right) \cdot \frac{I^{*}}{N}\right],
$$

where $k=(x, 3)$ if $i=(x, 2)$ and $k=(x, 2)$ if $i=(x, 3)$, and $N_{i}$ is the mass of individuals in occupation $i$ (that is, those working normally and those working from home combined). This captures the idea that the infection rates can be more sensitive to the mass of infected coworkers (managers and workers) than the mass of the infected general public.

\footnotetext{
${ }^{5}$ The government cannot observe anyone's true epidemiological state either. The enforcement applies equally to everyone in quarantine (group $i=q)$.
} 


\subsection{Government Policies}

We consider three types of government policies in the model: testing, tracking, and lock-down.

1. Testing. Equations (10)-(11) introduced $\tau^{a}$ and $\tau^{s}$, the fractions of asymptomatic and symptomatic people who are tested, after the spread of the virus within a period. Testing the asymptomatic can be viewed as "tracing," a policy testing all the people who have come into contact with a positively confirmed person even if they are asymptomatic.

2. Tracking. Tracking means an effective enforcement of quarantine, as measured by the variable $Q$ in (12). An effective tracking ensures that those who should be home are indeed staying home and not infecting others.

3. Lock-down. A lock-down forces people to work from home, as operationalized by $\rho_{x, j}$ in equation (9). People in our model decide whether to work normally or from home, so if a large enough a share of people are already voluntarily working from home, this policy is not binding. Furthermore, a lock-down mandates that certain people work from home but does not automatically ensure that they do not go out socializing and infecting others. In our language, tracking ensures that those in quarantine do indeed stay home.

The three policies are distinct and enter the model via separate sets of variables. A government can choose to implement any combination of them. In our benchmark calibration, we assume that SK adopts testing and tracking, while the UK adopts minimal testing and tracking accompanied by a lock-down.

\section{Quantitative Analysis: SK vs UK}

SK's response to COVID-19 has been lauded for its successful test and tracking policies. Thus, our benchmark calibration will be targeted to SK data on infections, recoveries and GDP losses. But precisely because its suppression of COVID was so successful, we will find that the fear factor (as measured by the parameter $\chi$ in our model) plays no role in explaining SK data unless it becomes so important that individuals no longer care about their earnings. Thus, we calibrate the fear factor along with an additional set of parameters for the UK, including its lock-down policy.

We then check the importance of the fear factor and the benefits of each country's policy by simulating the following counterfactual scenarios:

1. No intervention, SK and UK

2. SK's policy (high test and tracking) on UK

3. UK's policy (lock-down) on SK

4. Early or extended lock-down for UK

5. UK lock-down followed by virus "visas" on June 20th

Scenario 1 will illustrate how far-reaching the epidemic would have been absent any intervention. The remaining scenarios will show that, at least in our model, tracking is better than lock-downs, with a minimal effect on GDP. The last scenario will show 
that virus visas based on antibody tests are disproportionately beneficial for the lowskilled. This calls for redistributive antibody testing aimed at the low-skilled rather than random testing, as is called for in Germany.

\subsection{Calibration}

Economic parameters All the economic parameters are calibrated to SK. We fix the mass of the young population (ages 25-64) at 1 at time 0 , and the old (age 65+) at 0.26 , according to the population data from the Korean Statistical Information Service. Employment shares are computed from the Korea Labor Force Survey (KLFS), a monthly employment survey equivalent to the Current Population Survey in the United States. As shown in Table 1, the survey records whether an individual is self-employed with no workers (non-employers or single-worker firms) or an employer. We can also identify employees in a managerial position using their occupation code. Only the August includes a wage supplement and March is the most recently available iteration.

\begin{tabular}{|c|c|c|c|c|}
\hline August 2019 & Self-employed & Employer & Manager & Worker \\
\hline Low-wage industries & 3,522 & 1,152 & $\begin{array}{c}159 \\
(2.46)\end{array}$ & $\begin{array}{l}11,068 \\
(1.66)\end{array}$ \\
\hline High-wage industries & 605 & 382 & $\begin{array}{c}205 \\
(2.86)\end{array}$ & $\begin{array}{l}9,127 \\
(2.04)\end{array}$ \\
\hline February 2020 & Self-employed & Employer & Manager & Worker \\
\hline Low-wage industries & 3,398 & 1,109 & 148 & 10,942 \\
\hline High-wage industries & 626 & 351 & 192 & 9,110 \\
\hline March 2020 & Self-employed & Employer & Manager & Worker \\
\hline Low-wage industries & 3,510 & 1,072 & 150 & 10,719 \\
\hline High-wage industries & 629 & 325 & 198 & 8,989 \\
\hline
\end{tabular}

Table 1: Employment in SK (in thousands)

Self-employment: single employer-employee; Employer: self-employed with non-zero employees; Manager: employees in a managerial position. Monthly wage information (in parentheses, million KRW) is only included in the August supplement. Both employment counts and wages are inferred by using sample weights on 35,000 observations. Source: Korea Labor Force Survey.

Low- and high-skill workers in our model are differentiated by effective productivity $(z)$, as well as their productivity when working from home. Since the latter largely varies by industry (Hensvik et al., 2020), we broadly classify industries into low- and high-wage industries as follows so that low-skill workers' employment share is approximately 60 percent:

1. Low-skill $(l)$ : Transportation \& warehouses, Construction, Retail \& wholesale, Real estate, Support, Personal services, Health \& social assistance, Arts, sports \& Entertainment, Agriculture, Foods and accommodations 


\begin{tabular}{lll}
\hline Parameter & Value & Description \\
\hline$L_{y}$ & 1 & Mass of young \\
$L_{o}$ & 0.2562 & Mass of old \\
\hline$L_{l, j}^{0}$ & {$[0.1343,0.0500,0.4221]$} & $\begin{array}{c}\text { Initial employment share } \\
\text { by industry/occupation }\end{array}$ \\
$L_{h, j}^{0}$ & {$[0.0231,0.0224,0.3481]$} & Home productivity discounts \\
$\psi_{l, j}^{0}$ & {$[0.10,0.10,0.07]$} & by industry/occupation \\
$\psi_{h, j}^{0}$ & {$[0.70,0.70,0.49]$} & Sick productivity discount \\
$\phi$ & 0.7 & Effective productivities \\
\hline$z_{l, j}$ & {$[0.9167,1.0,1.0]$} & by industry/occupation \\
$z_{h, j}$ & {$[1.3594,1.3,1.3]$} & Sickness disutility \\
$\kappa$ & 0.1115 & Manager income share by industry \\
$\alpha_{l}, \alpha_{h}$ & {$[0.1493,0.0827]$} & Low-skilled share in final good production \\
$\theta$ & 0.4540 & Extreme value distribution \\
\hline$\mu_{q}, \sigma$ & {$[0.4667,0.3333]$} & for home-work choice \\
$\mu_{l, j}$ & {$[0,-0.9832,1.2349]$} & Extreme value distribution \\
$\mu_{h, j}$ & {$[0,-0.0145,2.8562]$} & for occupation choice \\
$\nu$ & 0.01 & $1 \%$ of individuals can switch occupation \\
\hline
\end{tabular}

Table 2: Economic Parameters

2. High-skill $(h)$ : Utilities, Finance, Professional, Information, Manufacturing, Mining, Public, Education

High-skill industries generally require less social interaction at the workplace. However, since we also let home-productivity vary by occupation, we will discount high-skill workers' productivity more than the high-skill self-employed and managers.

As shown in the table, employment shares remained roughly constant in SK, despite its early COVID-19 outbreak in February (compared to the UK) and the drop in industrial production of approximately 3.5 percent in February 2020 (month-to-month, seasonally adjusted). Thus, we consider the August employment and wage statistics to constitute an initial steady state.

We use KLFS August to calibrate a subset of the economic parameters as follows. First, we initialize employment shares, $L_{x, j}^{0}$ by skill and by assuming the self-employed $(j=1)$ and workers $(j=2)$ in the model respectively correspond to self-employed and to non-manager employees in the KLFS, and managers $(j=3)$ in the model to employers and employees in managerial positions in the KLFS. Employment shares are shown in the second panel of Table 2 .

We then set, for now, the home and sick productivity discounts arbitrarily, making sure that low-skill jobs and workers suffer heavier discounts, as shown in the third panel. Given these parameters, we calibrate $z_{x, j}, \kappa, \alpha_{x}$ and $\theta$ as follows. Suppose that there is no epidemic, so the fear factor is irrelevant. Also suppose that there is no preference shock, neither for working from home decisions nor occupation choices.

1. We normalize manager-worker productivities to be equal and set high-skill work- 
ers to be 30 percent more productive than low-skill workers. ${ }^{6}$ We then choose the self-employed productivity, $z_{x, 1}$, so that they are indifferent between staying self-employed or becoming a manager.

2. We choose $\kappa$ so that high-skilled are indifferent between working from home or not when sick. This ensures that low-skilled would never work from home, before realization of the i.i.d. preference shock to stay home.

3. We assume that only high-skill self-employed and managers work from home when sick. Then we can compute the manager share parameter $\alpha_{x}$ to match manager income shares from the KLFS. We can also set $\theta$ to match the low-skill income share in the KLFS, assuming that self-employed and employer mean wages are equal to managers'.

Given these parameter values, we then simulate the economy with no epidemic. We assume that the i.i.d. preference shocks for the work-from-home choice are drawn from extreme value distributions with location parameters $\left(\mu_{n}, \mu_{q}\right)$ and scale parameter $\sigma$, with the normalization $\mu_{n}=0$. For the preference shocks when making occupation choices, we normalize the scale parameter to one and the self-employment location parameter to $\mu_{x, 1}=0$. We calibrate these location and scale parameters as follows:

1. Choose $\mu_{q}$, the location parameter of the home preference shock, so that approximately 15 percent of high-skill self-employed and managers work from home. Then choose the scale parameter, $\sigma$, so that approximately 10 percent of low-skill self-employed and managers work from home (Eurostat, 2020; Hensvik et al., 2020).

2. Choose $\mu_{x, 2}, \mu_{x, 3}$, the location parameters for becoming a manager or worker, to match initial employment shares $L_{x, j}^{0}$.

Last, we arbitrarily assume that only $\nu=0.01$ of individuals can switch occupations. The resulting parameters are shown in the bottom panel of Table 2.

Epidemiology and policy parameters Figure 2 shows the path of SK's confirmed infections, recoveries and deaths from COVID-19 from January 21 to April 21. We show the same data for the UK for comparison.

Since policies affect the path of the virus, for the model to match the paths observed in Figure 2, the infection, recovery and mortality rates must be jointly calibrated with the policy parameters. Several of the SIR parameters are fixed loosely based on what is known up to now about SARS-CoV-2.

1. Assume a natural death rate of 0 for the young, and a 2 percent annual death rate for the old, based on SK mortality rates.

2. Uniformly set a recovery rate of $\gamma=1 / 14$ for the young, so that the infected remain infectious for two weeks. We then assume that it takes twice as long for the old to recover, or $\gamma_{o}=1 / 28$.

3. Assume that the old experience a 10 times higher mortality rate, conditional on contracting the coronavirus (Center for Disease Control and Prevention, 2020).

\footnotetext{
${ }^{6}$ These normalizations are innocuous, since in our model, the productivity parameters are not separately identified from the manager share $\alpha$ and low-skill share $\theta$.
} 


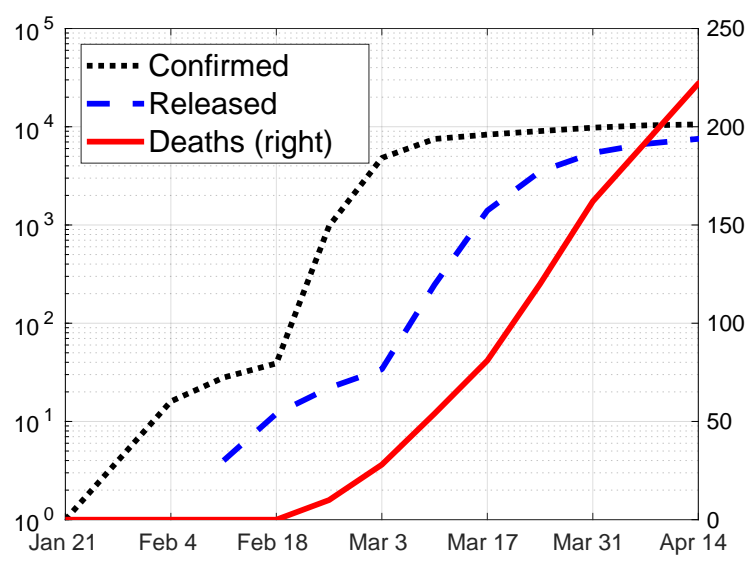

(a) South Korea

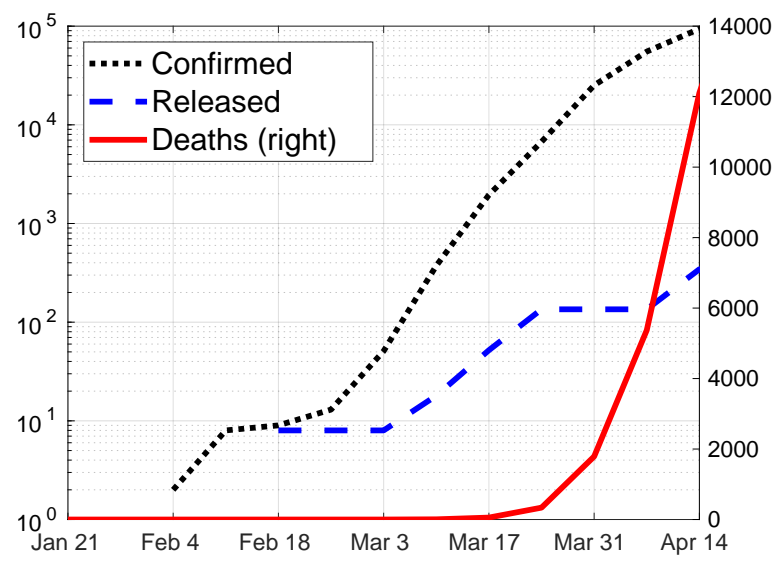

(b) United Kingdom

Fig. 2: Infections, Recoveries and Deaths, Cumulative: SK vs. UK

Confirmed and released in log-10 scale (left), death counts on the right axis. Source: Korea Center for Disease Control and Prevention, UK Department of Health and Social Care

4. Fix the infection rate of low-skill equal to the old. Fix the high-skill infection rate to 90 percent of the old, and those in quarantine to $1 / 7$ of the old. This assumes that a person in quarantine makes one day worth of social contact per week compared to a low-skill worker who does not work from home. High-skill jobs face lower infection rates to capture the fact that they are in better health in general and have better healthcare (Case and Deaton, 2020), and also require less social interaction at the workplace (Hensvik et al., 2020).

5. Suppose that workers and managers socialize more amongst themselves, and more so for high-skilled. This is to capture the fact that high-skill industries are more hierarchical.

Once these assumptions are made, there are four remaining parameters that determine the progression of the virus absent any policy intervention: the COVID-19 mortality rate of the young, the COVID-19 infection rate of the old, the initial date the coronavirus is introduced, and the initial mass of the infected on that day $\left(I_{0}\right)$. Since the latter two are not separately identified (we can always choose an earlier date assuming a lower mass of initially infected, and or the other way around), we arbitrarily set the initial date to December 22, 2019, which is exactly one month before SK starts publishing infection counts. Thus, confirmed cases start appearing on $\tau=30$.

We find that we cannot match the UK data using the same baseline infection and mortality rates $\left(v_{o}, m_{o}\right)$ as $\mathrm{SK}$, even taking into account different policies. ${ }^{7}$ So while we let these two parameters differ between SK and UK, to more easily compare the effect of policies, we keep all other epidemiology parameters equal between them. ${ }^{8}$ Of course, to the extent that UK employment shares and earnings are different from SK's,

\footnotetext{
${ }^{7}$ Thus, if the low infection and death counts in SK are due to policies, they are beyond something we can capture with our test/trace/tracking policies. Of course, at least some of the differences are due to different demographics, social interaction patterns, medical systems, etc., which are reflected on the baseline infection and mortality rate differences between the two countries.

${ }^{8}$ While the model is quantified to match each country, one can also view SK as a low infection/mortality economy, and UK as a high infection/mortality economy.
} 


\begin{tabular}{lll}
\hline Parameter & Value & Description \\
\hline$\delta_{y}$ & 0 & Young daily natural death rate \\
$\delta_{o}$ & $5.48 \mathrm{e}-05$ & Old annual natural death rate of 2 percent \\
\hline$\gamma_{y}$ & $1 / 14$ & Young recover in 2 weeks \\
$\gamma_{o}$ & $\gamma_{y} / 2$ & Old recover in 4 weeks \\
\hline$v_{o}$ & $(0.1555,0.1964)$ & Old infection rate to match $R_{0}=(2.18,2.75)$ in SK,UK \\
$v_{l, j}$ & $=v_{o}$ & Low-skill infection rate equal to old \\
$v_{h, j}$ & $=v_{o} \cdot 0.9$ & High-skill infection rate $90 \%$ of low-skill \\
$v_{q}$ & $=v_{o} / 7$ & Reduce social contact to 1 day a week in quarantine \\
\hline$\left[\beta_{l, 2}^{2}, \beta_{l, 2}^{3}\right]$ & {$[0.4,0.2]$} & Low skill manager interaction with managers and workers \\
{$\left[\beta_{l, 3}^{2}, \beta_{l, 3}^{3}\right]$} & {$[0.2,0.4]$} & Low skill worker interaction with managers and workers \\
{$\left[\beta_{h, 2}^{2}, \beta_{h, 2}^{3}\right]$} & {$[0.5,0.1]$} & High skill manager interaction with managers and workers \\
{$\left[\beta_{h, 3}^{2}, \beta_{h, 3}^{3}\right]$} & {$[0.1,0.5]$} & High skill worker interaction with managers and workers \\
\hline$m_{o}$ & $(0.0110,0.1096)$ & Old COVID mortality to match observed death counts in SK,UK \\
$m_{y}$ & $=m_{o} / 10$ & Young mortality from COVID one-tenth of the old \\
\hline$I_{0}$ & $1.27 \mathrm{e}-05$ & 500 people infected in SK on Dec 22nd $(t=0)$ \\
\hline
\end{tabular}

\section{Table 3: Epidemiology Parameters}

some of the results should be viewed with caution. However, the comparative dynamics would not vary much with the initial distribution of jobs and wages, as long as they are qualitatively similar.

Then we make the following assumptions on the testing technology, as well as the fraction of individuals who fall sick with or without the virus:

1. A fraction $1-\omega=0.2$ of test results are false-negative (Yang et al., 2020).

2. Rather optimistically assume that antibody testing becomes universal on June 19,2020 , or 180 days after the emergence of the virus.

3. Assume that 40 and 60 percent of the young- and old-infected are symptomatic, respectively (Mizumoto and Chowell, 2020).

4. Arbitrarily assume that 10 and 20 percent of the young and old are sick when uninfected, respectively.

Moreover, policy variables do not remain constant but change over time according to observed reactions of the SK and UK governments. All dates are number of days since Dec 22 .

Jan 21 First confirmed case in SK. Thus, we set $\tau=30$ for SK.

Jan 31 First confirmed case(s) in UK. Two people test positive. Thus, we set $\tau=40$ for UK.

Feb 10 UK health secretary announces strengthened quarantine policies $(t=50)$.

Feb 19 Shincheonji outbreak in SK, number of confirmed cases surge and country intensifies testing and tracking $(t=59)$.

Mar 15-23 UK announces the possibility of, then implements, a lock-down $(t=84)$ 


\begin{tabular}{|c|c|c|c|c|}
\hline Parameter & Value & \multicolumn{3}{|l|}{ Description } \\
\hline $\bar{\chi}$ & 10500 & \multicolumn{3}{|c|}{ Fear factor: 20 percent GDP drop in UK at peak infection } \\
\hline$\omega$ & 0.8 & \\
\hline$t_{A B}$ & 180 & \multicolumn{3}{|c|}{ Antibody test becomes universal } \\
\hline $\begin{array}{l}\left(f_{y}, f_{o}\right) \\
\left(\eta_{y}, \eta_{o}\right)\end{array}$ & $\begin{array}{l}(0.10,0.20) \\
(0.40,0.60)\end{array}$ & \multicolumn{3}{|c|}{$\begin{array}{l}\text { Old and young uninfected but sick } \\
\text { Young and old infected with symptoms }\end{array}$} \\
\hline $\begin{array}{l}\rho_{l, j} \\
\rho_{h, j}\end{array}$ & $\begin{array}{l}{[0.5,0.7,0.5]} \\
{[0.9,0.9,0.9]}\end{array}$ & \multicolumn{3}{|c|}{$\begin{array}{l}\text { Fraction low-skill locked-down } \\
\text { Fraction high-skill locked-down }\end{array}$} \\
\hline $\begin{array}{l}\lambda_{0} \\
\lambda_{1}\end{array}$ & $\begin{array}{l}0.66 \\
0.01\end{array}$ & \multicolumn{3}{|c|}{$\begin{array}{l}20 \text { percent GDP drop upon lock-down } \\
1 \text { percent decay in lock-down }\end{array}$} \\
\hline $\begin{array}{l}\left(\tau_{a}, \tau_{s}\right) \\
Q=\bar{Q}\end{array}$ & $\begin{array}{l}\text { [timeline below] } \\
\text { [timeline below] }\end{array}$ & \multicolumn{3}{|c|}{$\begin{array}{l}\text { Test rates for a/symptomatic } \\
\text { Tracking policy }\end{array}$} \\
\hline Country & Date & Event & Testing & Tracking \\
\hline SK & $\begin{array}{l}\text { Dec } 22, t=0 \\
\text { Jan } 21, t=30=\tau \\
\text { Feb } 19, t=59\end{array}$ & $\begin{array}{l}\text { No detection } \\
\text { First detection } \\
\text { Shincheonji outbreak }\end{array}$ & $\begin{array}{l}\left(\tau_{a}, \tau_{s}\right)=0 \\
\left(\tau_{a}, \tau_{s}\right)=0.001 \\
\left(\tau_{a}, \tau_{s}\right)=1\end{array}$ & $\begin{array}{l}Q=0 \\
Q=0.6 \\
Q=1\end{array}$ \\
\hline \multirow[t]{2}{*}{ UK } & $\begin{array}{l}\text { Dec } 22, t=0 \\
\text { Jan } 31, t=40=\tau \\
\text { Feb } 10, t=50 \\
\text { Mar } 15, t=84=t_{\lambda}\end{array}$ & $\begin{array}{l}\text { No detection } \\
\text { First detection } \\
\text { First quarantine } \\
\text { Effective lock-down }\end{array}$ & $\begin{array}{l}\left(\tau_{a}, \tau_{s}\right)=0 \\
\left(\tau_{a}, \tau_{s}\right)=(0,0.0005) \\
\left(\tau_{a}, \tau_{s}\right)=(0,0.005) \\
\left(\tau_{a}, \tau_{s}\right)=(0,1)\end{array}$ & $\begin{array}{l}Q=0 \\
Q=0 \\
Q=0.005 \\
Q=0.005\end{array}$ \\
\hline & Jun $20, t=180=t_{A B}$ & Hypothetical virus-visas & $\left(\tau_{a}, \tau_{s}\right)=(1,1)$ & $Q=0.005$ \\
\hline
\end{tabular}

\section{Table 4: Fear Factor and Policy Parameters}

We assume that the date of the first confirmed case is the date testing commences in the model, from which time onward all untested symptomatic and confirmed are quarantined. The test probabilities $\left(\tau_{a}, \tau_{s}\right)$, as well as quarantine enforcement $Q$, change values at each node of each country's timeline, but remain constant until another action is taken. The values of the parameters in each time interval are chosen to match the observed path of confirmed infections in each country in each time interval.

To capture the effect of testing, tracking, lock-downs, and virus visas, we specify the function $\rho_{x, j}(e)$, the intensity at which the government prevents people from working in equation (9), as

$$
\rho_{x, j}(e)= \begin{cases}\max \left\{\frac{\bar{\rho}_{x, j}}{1+\exp \left(\lambda_{0}+\lambda_{1}\left(t-t_{\lambda}\right)\right)}, \bar{Q}\right\} & \text { if } e \in\left\{s^{0}, a^{c}, s^{c}\right\} \\ \frac{\bar{\rho}_{x, j}}{1+\exp \left(\lambda_{0}+\lambda_{1}\left(t-t_{\lambda}\right)\right)} & \text { otherwise. }\end{cases}
$$

where $t_{\lambda}$ is the date a lock-down commences.

1. Tracking: Absent a lock-down, $\bar{\rho}_{x, j}=0$ for all $(x, j)$. Thus, the government can only quarantine the untested and confirmed with intensity $\bar{Q}$. Since $\bar{Q}$ is also a measure of testing and tracking policies, we simply set $\bar{Q}=Q$.

2. Lock-down: Implemented at time $t=t_{\lambda}$, a fraction $\bar{\rho}_{x, j}(e)$ individuals of skill $x$ in occupation $j$ are told to stay home, regardless of their symptoms. The function varies by skill and occupation, but not by observed epidemiological status. If more 
people in a certain state are voluntarily staying home, this policy is not binding. However, the intensity at which this is enforceable decays over time, where $\lambda_{0}$ measures the intensity of the policy upon impact and $\lambda_{1}$ the duration. ${ }^{9}$

3. Virus visas: The government sets $\bar{\rho}_{x, j}(e)$ to 0 for $e \in\left\{a^{r}, s^{r}\right\}$, while maintaining the same intensity as a lock-down for everyone else.

We set $\rho_{x, j}=0.5$ for low-skill self-employed and workers, 0.7 for low-skill managers, and 0.9 for all high-skill. While somewhat arbitrary, this captures the fact that the "essential workers" during the COVID-19 crisis are concentrated among low-skill industries and sectors, such as grocery workers, deliverers and security staff.

Finally, the fear factor itself plays a similar role as policy: If people fear the infection enough, they will voluntarily stay home, and more so when infection rates are higher. This would reduce the spread of the virus, but also drag productivity down. For simplicity, we assume that

$$
\chi_{i}(\mathbf{I}, e)= \begin{cases}0 & \text { if } e \in\left\{a^{r}, s^{r}\right\} \\ \bar{\chi} \cdot v_{i}(\mathbf{I}) & \text { otherwise. }\end{cases}
$$

Thus the constant $\bar{\chi}$ measures the fear factor. The fear factor and the lock-down parameter $\lambda_{0}$ jointly determine the initial drop in GDP upon implementation of the lock-down. Since the exact magnitude is yet unknown, we target a 20-percent drop in GDP both upon implementation of the lock-down and at the peak of infection, which is about the average of the IMF and UK Office for Budget Responsibility's GDP forecasts for the UK of $6.5 \%$ and $35 \%$, respectively. ${ }^{10}$ The duration parameter $\lambda_{1}$ is set arbitrarily at 0.01 , so that the effectiveness of the lock-down decays by $1 \%$ daily on the date of implementation.

The resulting epidemiology, policy and fear factor parameters are summarized in Tables 3 and 4 . While the test rates are chosen to match the observed infection counts, the mass of people tested should not be taken literally. As a policy, it measures how available testing procedures are. In SK, for example, testing costs approximately $\$ 40$, which is reimbursed if tested positive, so the actual cost is low. This made testing available to the general public regardless of symptoms, but at the same time, the government traced all individuals who came into contact with a confirmed person. Thus we set testing rates to $\tau_{a}=\tau_{s}=1$ in SK from February 19 onward. The fact that $Q=1$ in SK captures its digital tracking system, which maybe infeasible if infections grew larger but near perfect for its current level.

In contrast, tracing was never done in the UK, and strict self-quarantines are still more or less voluntary even in the midst of the lock-down. So we maintain $Q$ at its low level, even as more people are told to go home following the lock-down. Moreover, testing is still symptoms-based $\left(\tau_{a}=0\right)$ and not readily available even for many people with symptoms even now. Thus while $\tau_{s}=1$ during the lock-down is an optimistic representation of its policy, we maintain its high level both to match the data but also to give a lock-down policy a chance. ${ }^{11}$ In any case, we find that both a high $\tau_{a}$ (testing

\footnotetext{
${ }^{9}$ Thus, $\lambda_{1}$ not only measures how strongly the government implements a lock-down, but also how willingly people follow the rules.

${ }^{10}$ Because SK effectively contains the virus early on, the fear factor never becomes quantitatively operational. Thus we cannot use SK moments to discipline $\bar{\chi}$.

${ }^{11}$ We are still able to match UK's infection path with slightly lower levels of $\tau_{s}$, but that would lead to higher calibrated values for UK's infection probability parameters.
} 


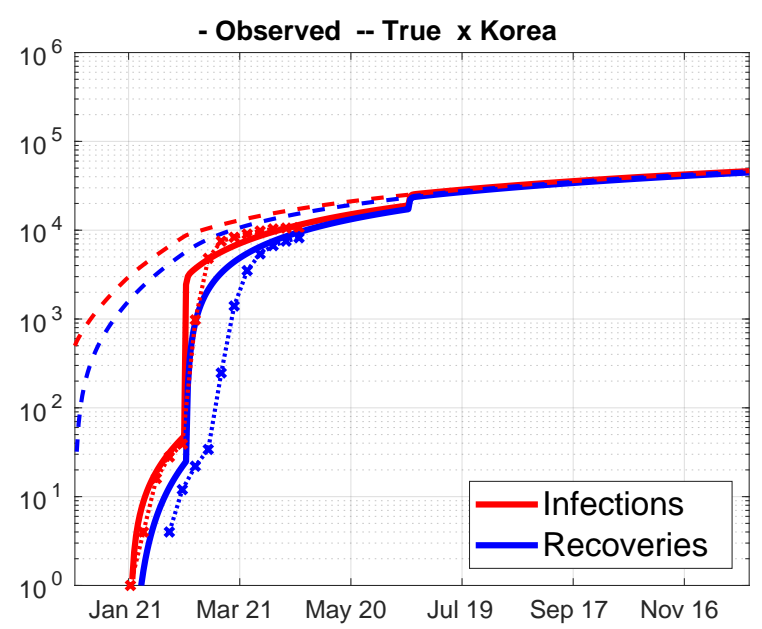

(a) Infections and Recoveries

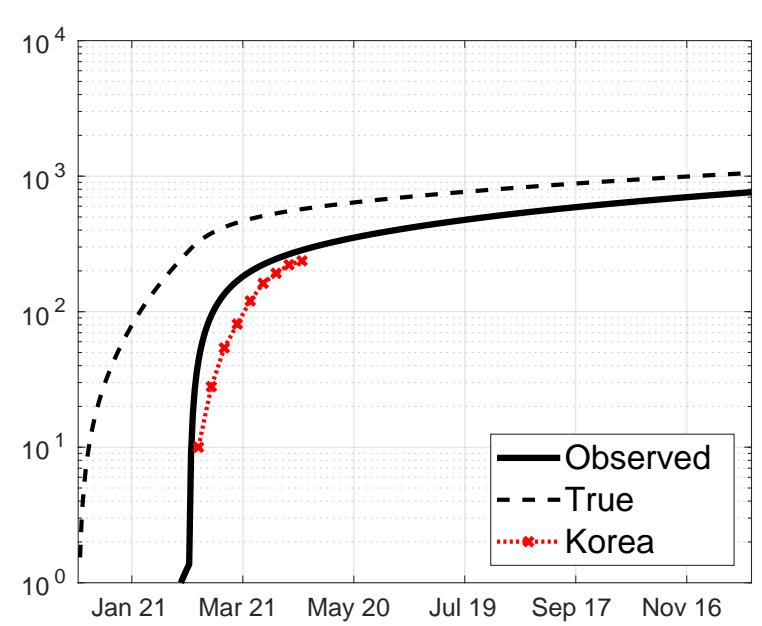

(b) Deaths

Fig. 3: SK SIR Model vs. Data

"Observed" corresponds to confirmed cases in the model. Counts are cumulative and in log-10 scale. Data source: Korea Center for Disease Control.

of asymptomatic) and high $Q$ were necessary for SK's successful containment of the virus.

The results of our calibration are shown in Figure 3 and 4, for SK and UK, respectively. ${ }^{12}$ There are several points to note. First, the kinks in the model infection curves represent a change in policy in each country, which do not perfectly align with the data but track its general path. Second, for a fair comparison, we have chosen parameters so that our model slightly overshoots SK and undershoots UK, especially given that the latter has higher infection and mortality rates. Third, there are discrepancies in UK's data reporting, for both recoveries and deaths. It is quite clear that recoveries are not being reported daily, and also that information on deaths were not released until later. Finally, the model captures that both SK's test/trace/tracking policy and UK's lock-down have effectively "flattened the curve," at least for now.

\subsection{GDP and Inequality}

Given that the model matches infection and death counts for each country, how much did the containment policies matter for economic outcomes? First, in Figure 5, we plot together low-skill, high-skill and aggregate GDP (not in per capita, to capture the deaths from the virus), for both countries.

SK's GDP loss from January to March grows from 2.7 percent to 5.2 percent, which is very close to the actual industrial production drop of 3.5 percent in the data. Since this drop was not a targeted moment, it is a success of our model. In contrast, the 20 percent drop in UK's GDP was a target moment. But notice that GDP already drops quite substantially even before the lock-down on March 15, which is partly due to the (weak) quarantine policies put in place before the lock-down but mostly due to the

\footnotetext{
${ }^{12}$ The model is in masses, while data is in integer counts. We blow up the mass for SK by 39,314,000, its age $25+$ population in 2018. For the UK, we blow up this number further by 29.32 percent, according to the population size from the Office of National Statistics.
} 


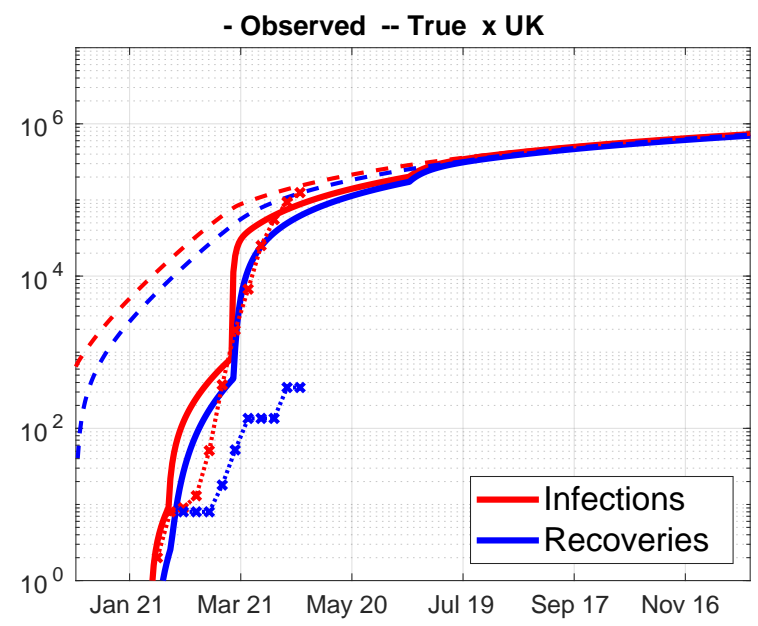

(a) Infections and Recoveries

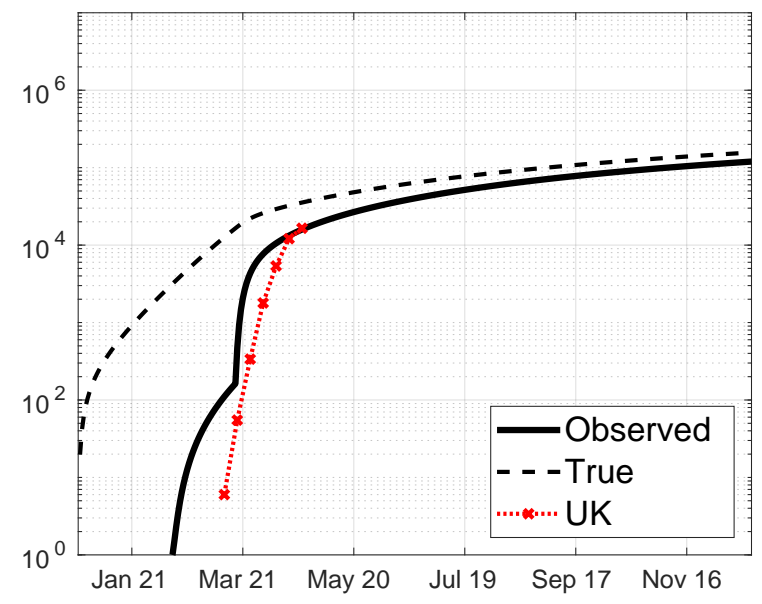

(b) Deaths

Fig. 4: UK SIR Model vs. Data

"Observed" corresponds to confirmed cases in the model. Counts are cumulative and in log-10 scale. Data source: UK Department of Health and Social Care.

fear factor. Since the lock-down weakens after impact, there is a small recovery until April, but then as the virus further progresses, GDP falls again due to the fear factor (calibrated to reach a trough of $20 \%$ ).

The fear factor is also why GDP falls between January and February in SK. However, the fact that GDP remains constant afterward implies that SK's policy successfully contained the virus, so that the fear factor is no longer binding for most people (and therefore there is no subsequent drop in GDP).

Perhaps more important, the drop in low-skill GDP is much larger than high-skill for both countries. This is because the low-skill are less productive from home. The relative drop is even larger when it is due to the fear factor. Even as high-skill GDP recovers in the UK, low-skill GDP continues to drop because low-skill workers face higher risks of infection at work and are thus more sensitive to the fear at very high infection rates. In fact, high-skill GDP recovers entirely by the time antibody tests become available on June 20, so the only reason total GDP remains low afterward is because low-skill GDP continues to drop to more than 40 percent below its initial value.

Earnings vary by occupation as well. In Figures 6 and 7, we plot together the earnings and employment shares of each skill-occupation group for SK and UK, respectively.

Employment shares in SK are close to constant, consistent with SK data in Table 1. ${ }^{13}$ Again, this implies that the fear factor is barely operational for individuals to switch jobs (from the steady state shares at $t=0$ ). However, earnings losses still vary considerably by occupation. The self-employed stand to lose the most both because of a higher fear factor (so they stay home more) and the tracking policy (as more of them are infected, more are enforced to stay home). But the policy is strong enough so that

\footnotetext{
${ }^{13}$ Moreover, despite the small magnitude both in the data and the model, the model-predicted employment share changes by skill-occupation are qualitatively in line with the January to March changes (from the first confirmed case to peak in SK) in the KLFS as well.
} 


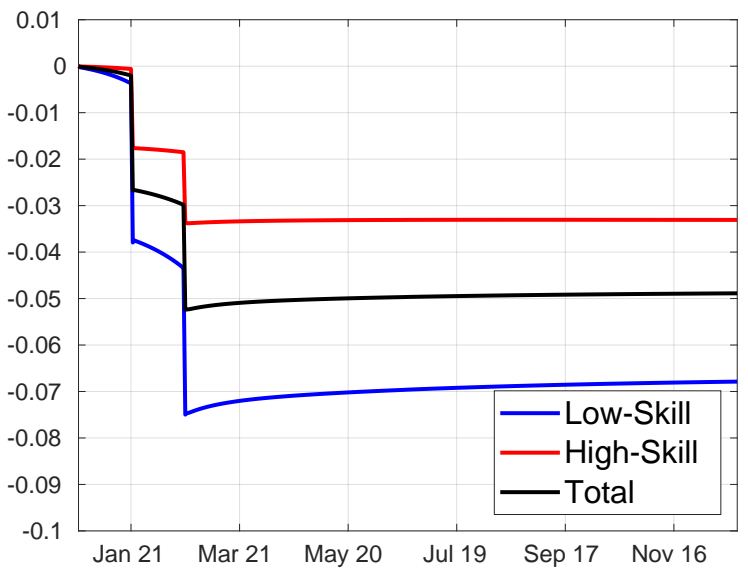

(a) SK

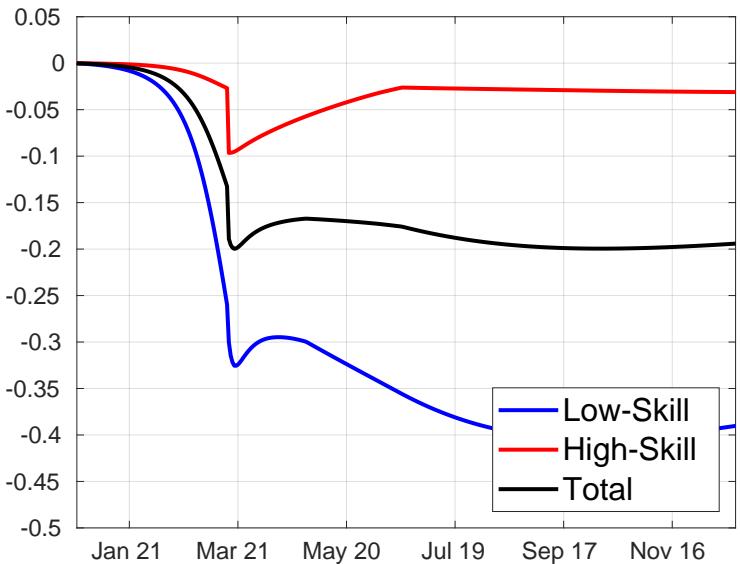

(b) UK

Fig. 5: GDP Losses: SK vs UK

Model implied GDP by skill, and total. GDP is in log-point changes and not normalized per capita, so includes GDP losses from COVID-19 deaths (the working-young has a zero natural death rate).

the fear factor wears off over time. In contrast, low-skill workers' earnings drop little upon policy impact, and drop only modestly over time. Workers are forced to work by their managers, so earnings drop by less no matter the rate of infection. But since they face higher rates of infection, more of them get sick and experience a productivity discount.

The changes in the UK are more dramatic, but it is still the low-skill self-employed who lose the most. Despite the large loss in earnings, their employment share goes up: This is due to low-skill workers switching their jobs to self-employment at high rates of infection. At very high rates of infection, workers value the option to stay home more than their earnings, so switch toward self-employment, as shown in Figure 7(b). And because so many workers switch to other jobs, their relative wages go up in equilibrium.

Thus, the rise in workers' earnings in Figure 7(a) must be viewed with caution. At high infection rates, workers would rather stay at home but are not given the choice. And in our model, the only way for workers to avoid infection is to switch jobs. Although we do not explicitly model unemployment, workers' switch toward self-employment would show up exactly as unemployment in the data. Workers in our model who switch their jobs to self-employment experience a drop in earnings of more than 90 percent. The low earnings they make in self-employment can be viewed as unemployment benefits or other government subsidies that are issued universally.

\subsection{Counterfactual Policy Analysis}

How effective were each country's policies? While SK's policy is deemed successful, would it work for other countries as well? And could an early lock-down have contained the outbreak better (or worse)? We address these questions by simulating the path of infections and GDP if each country had implemented no policies, and then applying the UK's policies on SK and vice versa.

In Figure 8, we compare SK's baseline policy against the hypothetical outcome 


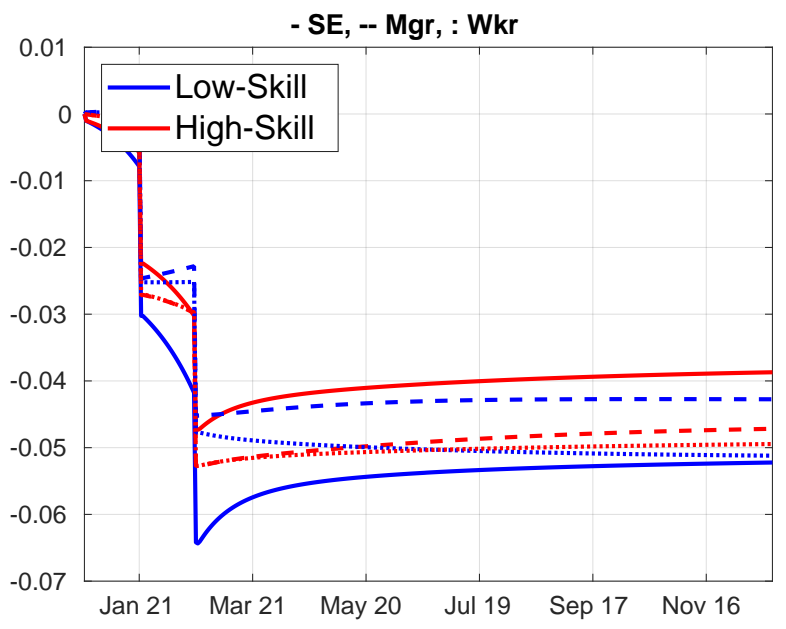

(a) Earnings

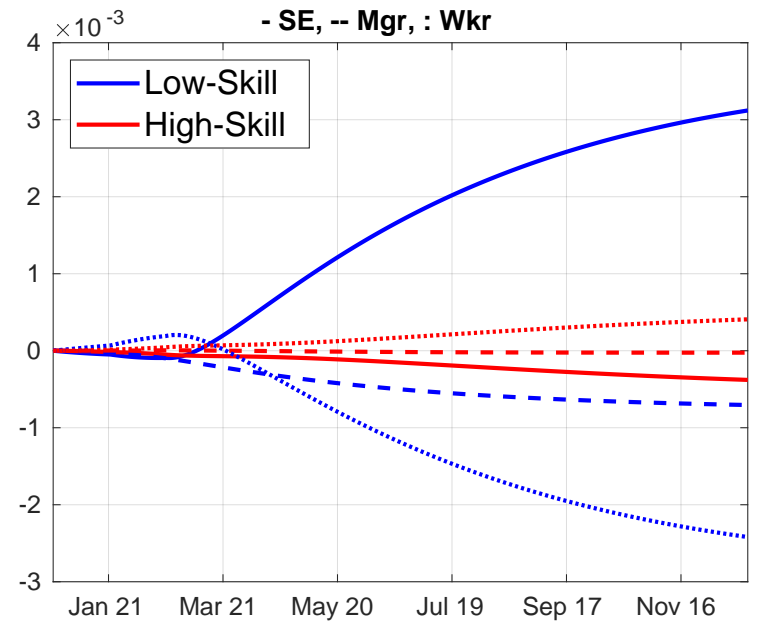

(b) Employment Shares

Fig. 6: SK Dynamics by Skill-Occupation Group

SE: Self-employed, Mgr: Managers, Wkr: Workers. Earnings are in log-point changes in per worker earnings, and employment shares in percentage point changes.

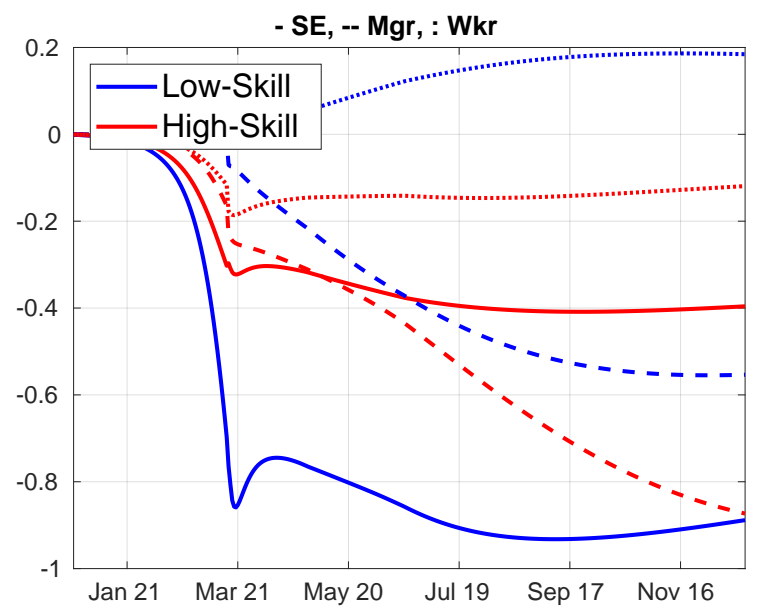

(a) Earnings

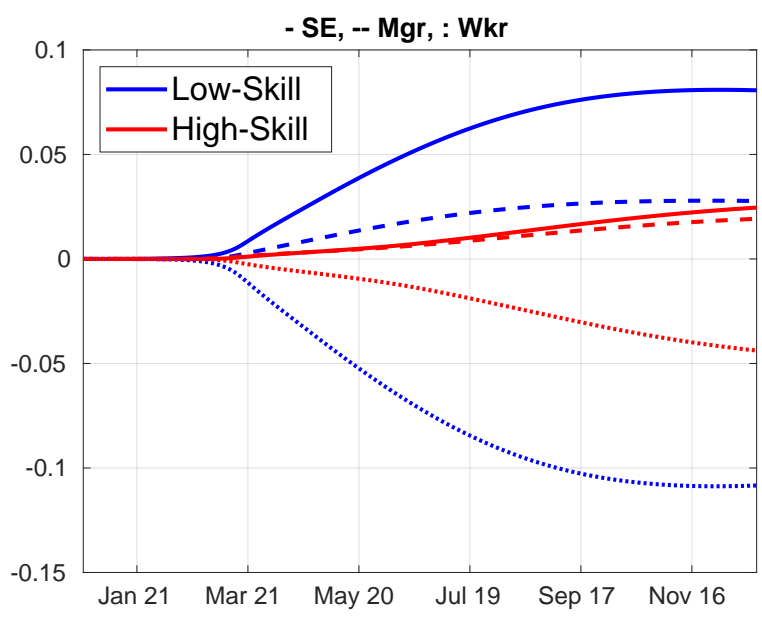

(b) Employment Shares

Fig. 7: UK Dynamics by Skill-Occupation Group

SE: Self-employed, Mgr: Managers, Wkr: Workers. Earnings are in log-point changes in per worker earnings, and employment shares in percentage point changes. 


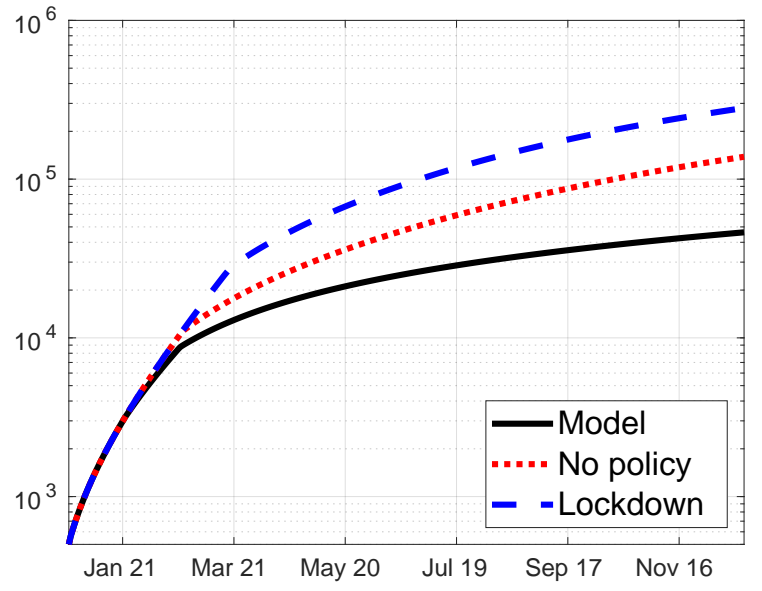

(a) Infections

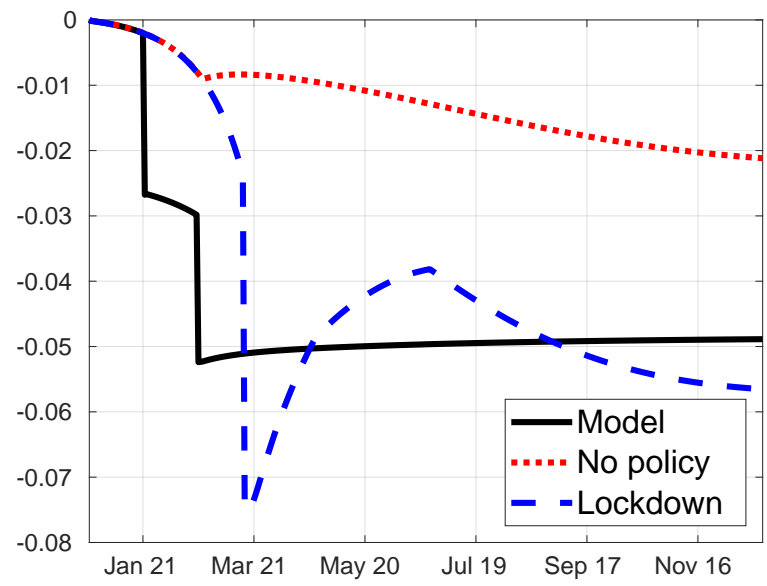

(b) Total GDP

Fig. 8: SK Counterfactual Policies

"Model" is SK's baseline test/trace/tracking policy. "No policy" is doing nothing, and "Lockdow" is if SK had followed UK's policy exactly, including its lock-down date. Infection counts are cumulative and in log-10 scale. GDP is in log-point changes and not normalized per capita, so includes GDP losses from COVID-19 deaths (the working-young has a zero natural death rate).

had it had not done anything, and had it instead implemented UK's lock-down policy, including the exact dates of implementation. Without any intervention, the virus would have spread twice as much (note that the $y$-axis is in log-10 scale), although the peak infection in SK would still have been low enough so that GDP loss due to the fear factor ( 2 percent) would have been smaller than its current policy ( 5 percent). More interesting, a UK style lock-down backfires: Not only does it result in larger GDP losses upon impact, it in fact promotes the spread of the virus in the long-run, leading to larger GDP losses in the long-run as well.

While somewhat paradoxical, this is due to two effects unique to our model. First, with little testing, quarantines are sending too many of the untested symptomatic home, most of whom are uninfected. But in our model, since infection rates depend on the infected at one's workplace, these people have less chance of getting infected at work than at home (as long as a smaller share of their coworkers infected than the aggregate). ${ }^{14}$ Note that this is despite the fact that the infection constant $\bar{v}$ is only one-seventh when in quarantine. Similarly, in the event of a lock-down, more high-skill than low-skill are sent home, but high-skill also have lower infection rates. So the lock-down policy is sending the wrong people home (those who would have faced lower infection rates at work).

Fortunately, this is not the case for the UK. In Figure 9, we compare UK's baseline policy against the hypothetical outcome had it had not done anything, and had it instead implemented SK's test/trace/tracking policy, including the exact dates of implementation. Without any intervention, the virus would have spread twice as much (note the lock-down in the UK reduces peak infection compared to doing nothing, preventing the impending 30 percent drop in GDP that would have been caused by large masses of people staying home at peak infection (in August). Nonetheless, if the UK

\footnotetext{
${ }^{14}$ For example, this captures the fact that leisure activities may spread the virus more than work activities.
} 


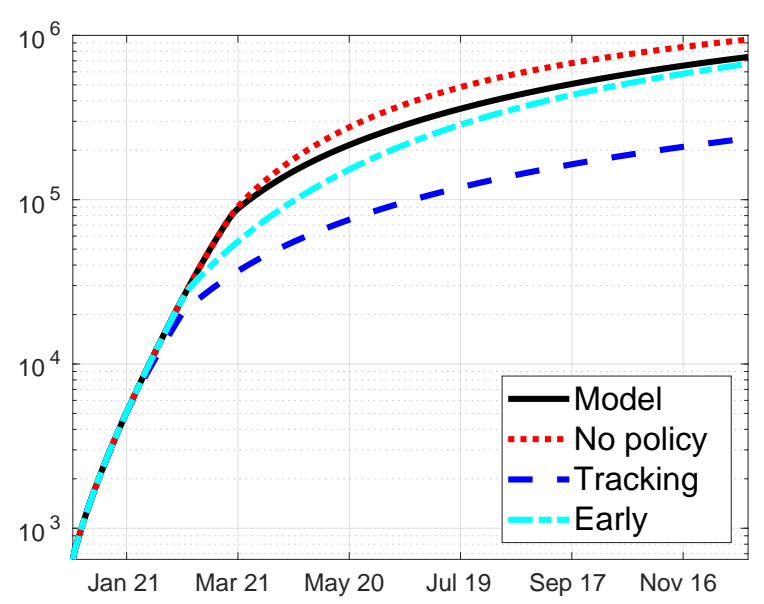

(a) Infections

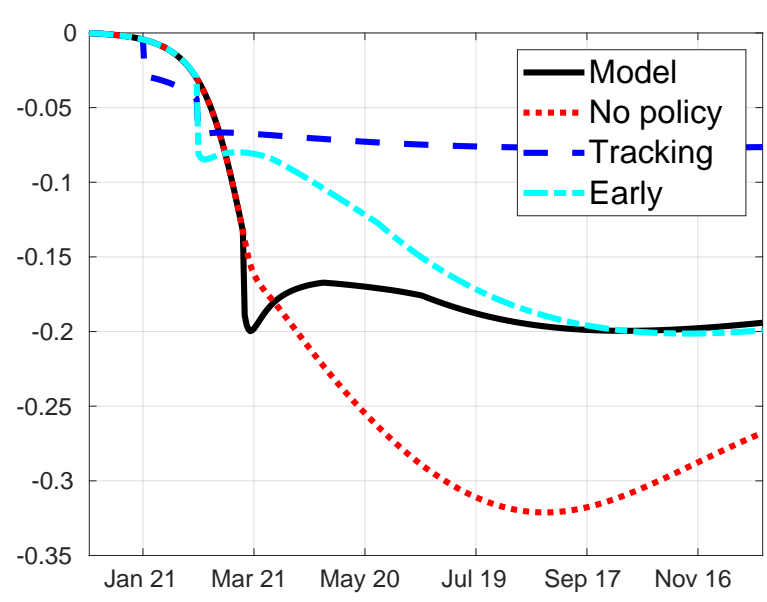

(b) Total GDP

Fig. 9: UK Counterfactual Policies

"Model" is UK's baseline lock-down policy. "No policy" is doing nothing, and "Tracking" is if UK had followed SK's policy exactly, including its timing. "Early" is if UK had implemented the same lock-down, but at the time of SK's Shincheonji outbreak. Counts are cumulative and in log-10 scale. GDP is in log-point changes and not normalized per capita, so includes GDP losses from COVID-19 deaths (the working-young has a zero natural death rate).

had implemented SK's testing policy, the virus would have been contained at an early stage, resulting in much less infections in the long-run, with only a modest drop in GDP (7 percent) compared to the 20 percent drop due to the lock-down. Thus, this shows that SK's policy is more effective regardless of the cross-country difference in infection and mortality rates.

But is it the policy itself, or the early reaction (in February rather than March) that leads to successful containment? To find out, we additionally simulate a path in which the lock-down is implemented at the same time as when SK intensified its testing policies. While an early lock-down is effective in preventing the spread of the virus upon impact, its efficacy wears off over time, and is not enough to avoid high infections in the long-run. Consequently, infections eventually reach almost the level of the later lock-down ("Model"), as well as similar losses in GDP by September.

Of course, the reason an early lock-down is perhaps not as effective as expected is due to the decay of its effectiveness, which we build into the model in Equation 13. While some of the decay can be due to civil disobedience, it may also be due to weak enforcement. Thus, in Figure 10, we additionally simulate the paths of infections and GDP if the decay parameter, $\lambda_{1}$, were equal to 0.001 rather than 0.01 (0.1 percent decay per day).

An extended lock-down reduces the cumulative infection count by more than 100,000 , thus dramatically reducing peak infection. Consequently, the extension of the lock-down is able to avoid the fear factor taking over the lock-down, and GDP continues to rise as the lock-down wears off, albeit slowly. To be specific, the extended lock-down results in 150,000 fewer infections and 5-percent higher GDP by November than the current policy. In other words, a stricter and longer lock-down can deliver both higher GDP and better public health outcomes.

An alternative policy to an extended lock-down is a "selective lifting" of the lock- 


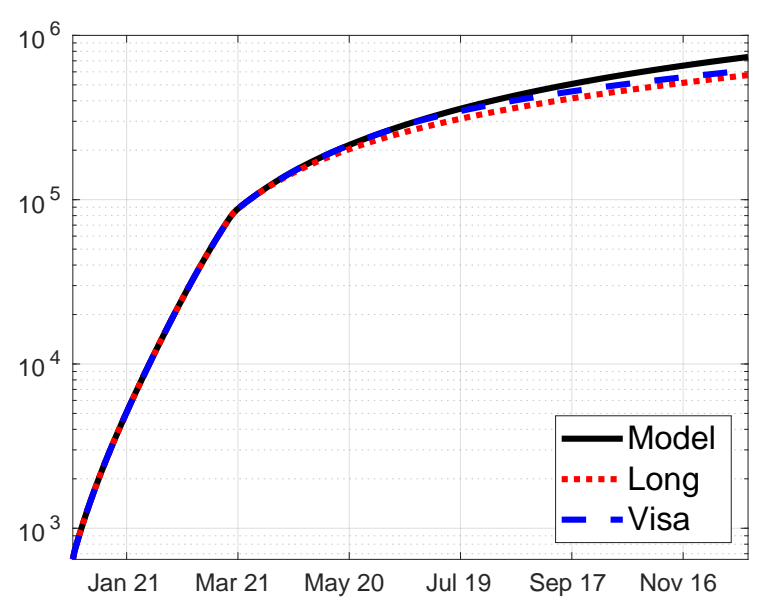

(a) Infections

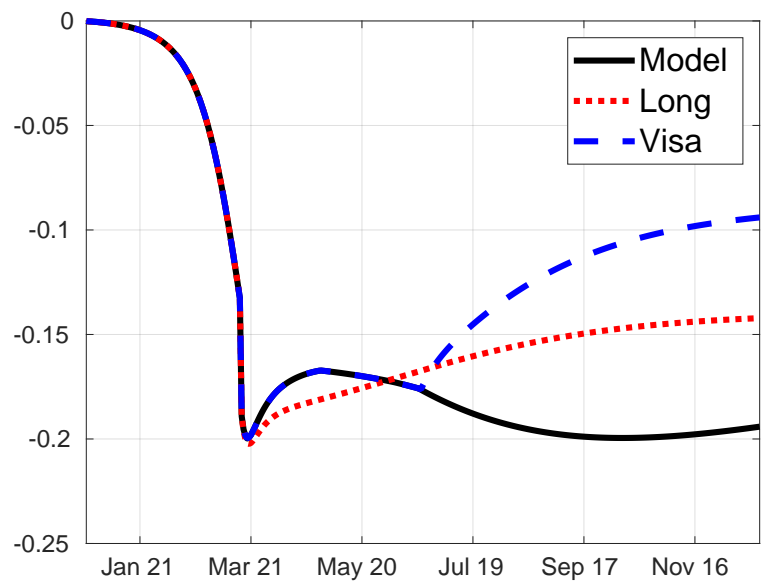

(b) Total GDP

Fig. 10: UK Counterfactual Policies: Extended Lock-Down and Virus Visas "Model" is UK's baseline lock-down policy. "Long" is an extension of the lock-down, which we simulate by reducing the decay of its effectiveness. "Visa" is if UK starts issuing antibody test-based virus visas once testing becomes available on June 20, 2020. Counts are cumulative and in log-10 scale. GDP is in log-point changes and not normalized per capita, so includes GDP losses from COVID-19 deaths (the working-young has a zero natural death rate).

down through the issuance of virus visas. For example, Germany is considering random testing (testing also the asymptomatic) as well as antibody tests. For comparison, we simulate the infection and GDP paths of the UK under a hypothetical scenario in which it starts issuing virus visas once antibody tests become universally available.

We assume that UK's baseline lock-down policy continues until June 20, at which point virus visas begin to be issued for all who have recovered from the virus. On this date, we also assume that both asymptomatic and symptomatic people are universally tested (meaning that antibody testing becomes available to all). As shown in Figure 10, widespread testing is as effective as an extended lock-down in reducing the spread of the virus. And by allowing all recovered to work, in addition to averting the GDP loss from the fear factor, long-run GDP is 10 percent higher than baseline by November. ${ }^{15}$ The fact that virus visas depend on antibody testing is crucial: Since more than half of eventually infected are already recovered by June 20, without it, the visa policy that can only vouch for the confirmed recovered has barely any effect.

\subsection{Virus Visas and Inequality}

GDP and earnings drops are always larger for the low-skill, regardless of whether it is due to policies or the fear factor. Since virus visas are effective in reducing both infections and GDP losses, we now compare the benefits of the policy across different skill and occupation groups in the UK.

Figure 11 shows the resulting changes in GDP by skill, utility, earnings, and employment changes by skill and occupation. Figure 11(a) is to be compared with Figure

\footnotetext{
${ }^{15}$ Since the policy successfully contains the virus, although belatedly, we find that additional SK-style tracking $(Q=1)$ does little to affect both the infection path and GDP.
} 


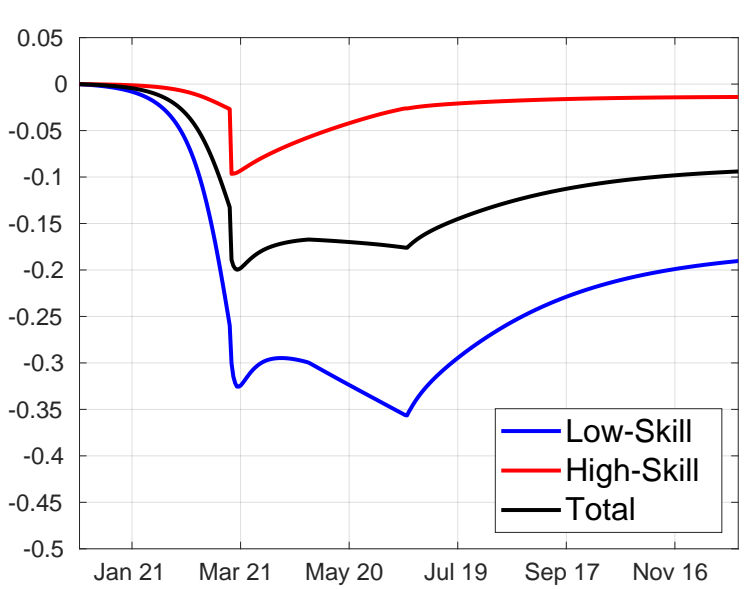

(a) GDP by Skill and Total

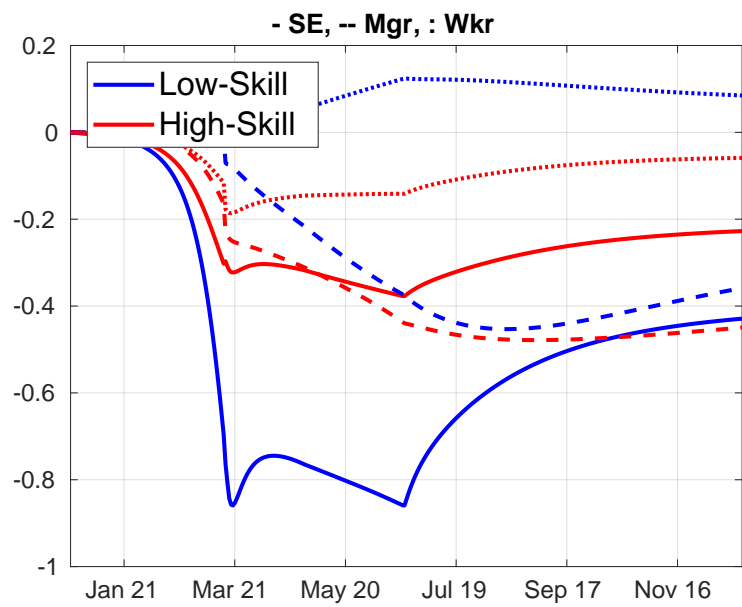

(c) Earnings by Skill and Occupation

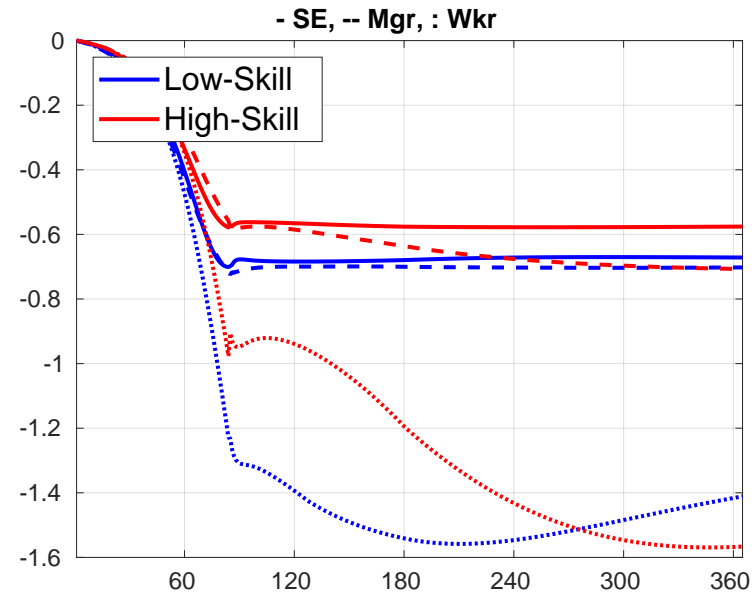

(b) Utility by Skill and Occupation

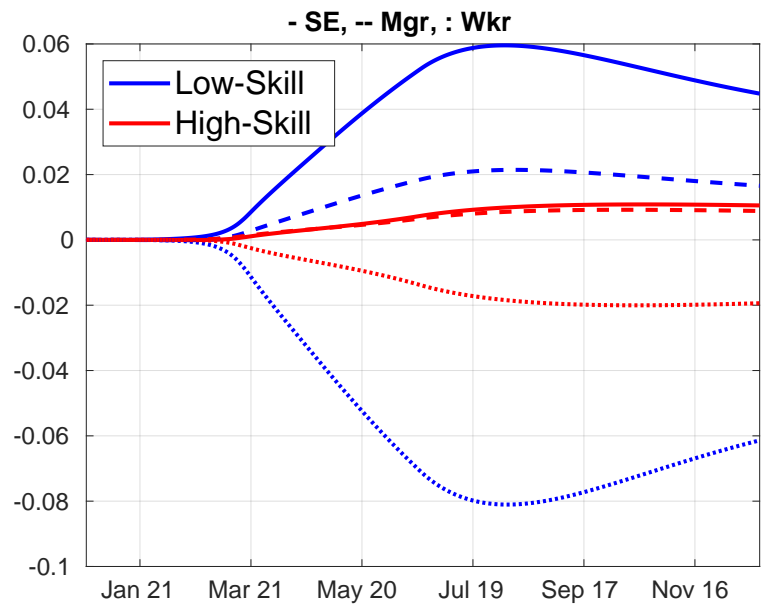

(d) Employment Shares by Skill and Occupation

\section{Fig. 11: UK Inequality using Hypothetical Virus-Visas}

SE: Self-employed, Mgr: Managers, Wkr: Workers. GDP is in log-point changes and not normalized per capita, so includes GDP losses from COVID-19 deaths (the working-young has a zero natural death rate). Utilities are in per worker level changes. Earnings are in log-point changes in per worker earnings, and employment shares in percentage point changes. 
5(b), and Figures 11(c) and 11(d) with Figure 7. Before June 20, the paths are exactly same as in the baseline, since up to then agents are subject to the same lock-down policy and individuals are not forward looking.

Just as the persistent drop in GDP was entirely driven by the low-skill in Figure 5(b), Figure11(a) shows that the recovery from the virus visa is also entirely driven by the low-skill. The reason for this is two-fold. On the one hand, low-skill self-employed earnings recover dramatically, as those who find out they have already had the virus and recovered return to work, as shown in Figure 11(c). On the other hand, low-skill workers, who experience the smallest change in earnings due to being forced to work during the lock-down, no longer switch to self-employment to avoid infection (where they have the choice to self-quarantine themselves), and even those who previously switched return to being a worker, as shown in Figure 11(d). As discussed in Section 3.2 , workers who switch to self-employment to avoid the virus in our model can be viewed as becoming unemployed. Thus, workers' recovery captures furloughed or laidoff workers returning to work once the fear of infection is gone.

This latter effect is more obvious in Figure 11(b), which shows the utilities of each skill-occupation group. There, it is clear that despite the low drop in earnings, it is the workers - and especially low-skill workers - who experience the largest drop in utility from being more exposed to the virus than other groups, as they do not have the choice of staying home even at high infection rates. The rise in their utility following virus visas cannot be due to earnings, which remain flat for the duration of the lockdown. Thus, their rise in utility is entirely due to the removal of the fear factor, as we assumed in (14). And as their utility begins to rise, they no longer switch jobs (or become unemployed) and some of those who had left their jobs in the past, despite the low earnings in self-employment (which can be viewed as low income in unemployment), return.

In summary, to the extent that (i) low-skill workers and self-employed lose the most in all scenarios, and (ii) the high-skill benefit less from virus visas, because by now their earnings and employment have more or less recovered, our counterfactual visa policy results call for redistributive antibody testing should it become availabledisproportionately intense testing for the low-skill. This not only helps those most in need, but also has the largest effect in recovering aggregate GDP.

\section{Conclusion}

We presented a quantitative economic-epidemiological model of the COVID-19 epidemic to investigate how different containment policies affect inequality, as well as aggregate outcomes. Individuals choose whether to work from home or not, and when infection rates are high, voluntarily choose to stay home out of fear of infection despite lower earnings. We show that, contrary to common beliefs, that containment policies mitigate not only infections but also long-run GDP losses, because losses would become even higher if the virus is not contained early and people start to self-quarantine themselves en masse. We also show that South Korea's testing and tracking policies are quantitatively much more effective at containing both the spread and GDP losses than a lock-down, regardless of the timing. Finally, we show that low-wage self-employed and workers suffer the most from the epidemic and the government countermeasures to it, and stand most to gain from virus visas based antibody tests, raising the possibility 
that redistributive testing is not only economically equitable but also efficient, in the sense that it would have a larger impact on raising aggregate GDP than randomly testing the same number of people.

Several of our parameters are chosen ad hoc and only loosely calibrated. However, as more data becomes available and allows us to use more informative numbers for calibration, our model of heterogeneous skills and occupations with observable and unobservable health status can serve as an ideal laboratory to guide our sense of how different policies have affected and will affect economic and (COVID-related) health inequality as we continue to battle the epidemic. 


\section{Bibliography}

Alvarez, F. E., D. Argente, and F. Lippi (2020, April). A simple planning problem for covid-19 lockdown. Working Paper 26981, National Bureau of Economic Research.

Case, A. and A. Deaton (2020). Deaths of Despair and the Future of Capitalism. Princeton University Press.

Center for Disease Control and Prevention (2020). Severe Outcomes Among Patients with Coronavirus Disease 2019 (COVID-19) — United States, February 12-March 16, 2020. MMWR and Morbidity and Mortality Weekly Report.

Chudik, A., M. H. Pesaran, and A. Rebucci (2020, April). Voluntary and mandatory social distancing: Evidence on covid-19 exposure rates from chinese provinces and selected countries. Working Paper 27039, National Bureau of Economic Research.

Eichenbaum, M. S., S. Rebelo, and M. Trabandt (2020, March). The Macroeconomics of Epidemics. NBER Working Papers 26882, National Bureau of Economic Research, Inc.

Eurostat (2020). How usual is it to work from home? Products Eurostat News.

Farboodi, M., G. Jarosch, and R. Shimer (2020, April). Internal and external effects of social distancing in a pandemic. Working Paper 27059, National Bureau of Economic Research.

Hensvik, L., T. L. Barbanchon, and R. Rathelot (2020). Which jobs are done from home? Evidence from the American Time Use Survey. Centre for Economic Policy Research Discussion Papers.

Kermack, W. O., A. G. McKendrick, and G. T. Walker (1927). A contribution to the mathematical theory of epidemics. Proceedings of the Royal Society of London. Series A, Containing Papers of a Mathematical and Physical Character 115(772), 700-721.

Krueger, D., H. Uhlig, and T. Xie (2020, April). Macroeconomic dynamics and reallocation in an epidemic. Working Paper 27047, National Bureau of Economic Research.

Lee, S. Y. and Y. Shin (2017, March). Horizontal and vertical polarization: Taskspecific technological change in a multi-sector economy. Working Paper 23283, National Bureau of Economic Research.

Mizumoto, K. and G. Chowell (2020). Transmission potential of the novel coronavirus (covid-19) onboard the diamond princess cruises ship, 2020. Infectious Disease Modelling 5, $264-270$.

Piguillem, F. and L. Shi (2020). Optimal COVID-19 Quarantine and Testing Policies. CEPR Discussion Paper 14613, Einaudi Institute for Economics and Finance (EIEF). 
Yang, Y., M. Yang, C. Shen, F. Wang, J. Yuan, J. Li, M. Zhang, Z. Wang, L. Xing, J. Wei, L. Peng, G. Wong, H. Zheng, M. Liao, K. Feng, J. Li, Q. Yang, J. Zhao, Z. Zhang, L. Liu, and Y. Liu (2020). Evaluating the accuracy of different respiratory specimens in the laboratory diagnosis and monitoring the viral shedding of 2019-ncov infections. medRxiv. 